
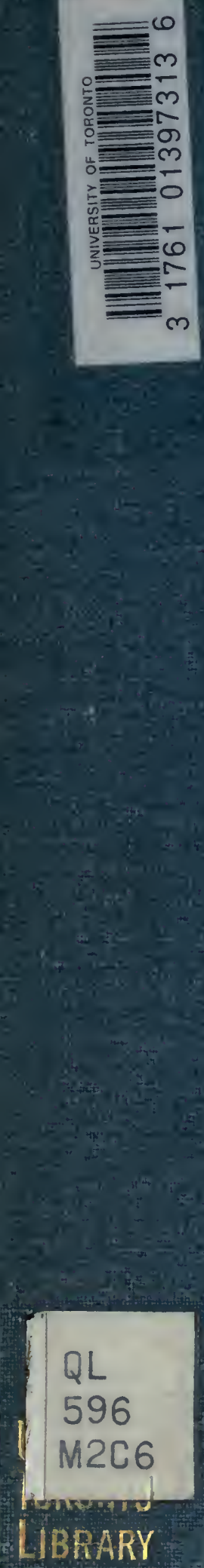




Digitized by the Internet Archive in 2008 with funding from Microsoft Corporation 


\section{A PHYSICAL STUDY OF THE FIREFLY}

WILIIIAM W. COBIENTTZ
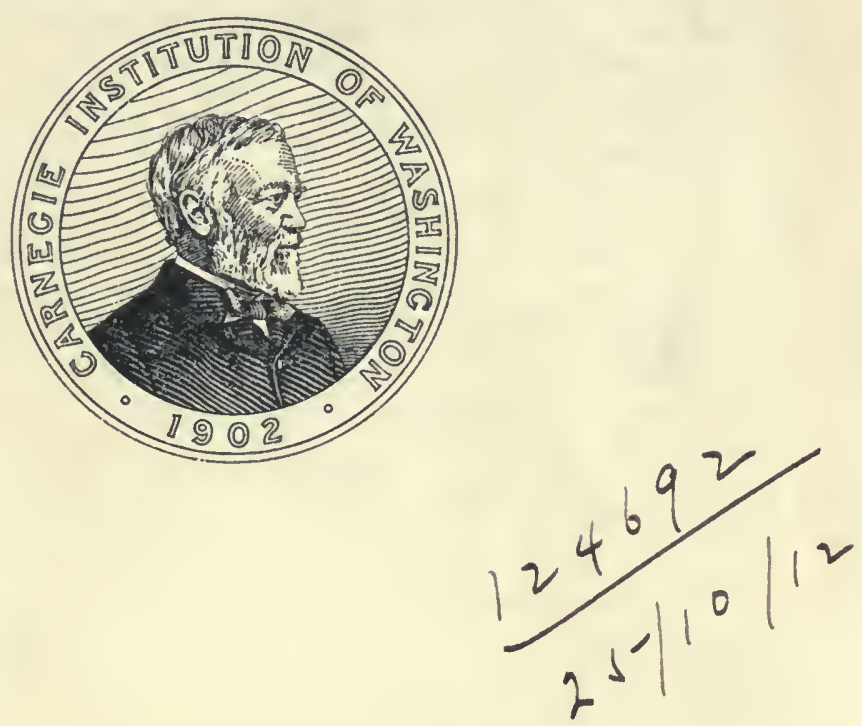

WASHINGTON, D. C.

Published ay the Carnegie Institution of Washington 
CARNEGIE INSTITUTION OF IVASHINGTON

Publication No. 164

$$
\begin{aligned}
& \text { QL } \\
& 596
\end{aligned}
$$

Copies of this Book M/2C6 were first issued APR 91912 


\section{A PHYSICAL STUDY OF THE FIREFLY.}

CONTENTS.

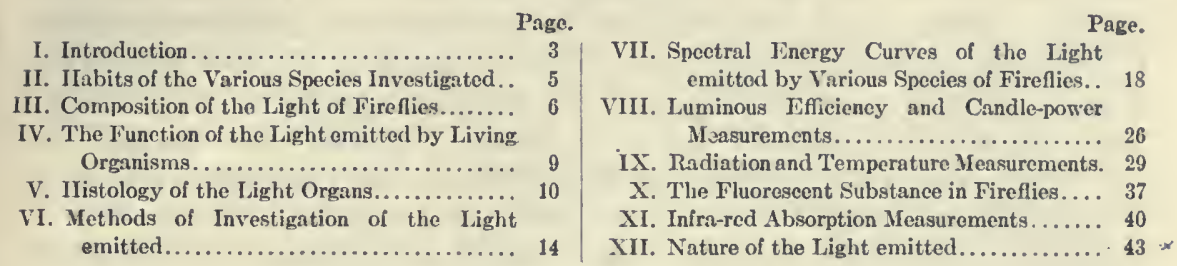

\section{INTRODUCTION.}

During the latter part of the summer of 1908 the first attempt was made to measure the radiation from the local species of firefly. The season was late and but little was accomplished beyond the acquisition of some knowledge of the habits of these interesting insects. 'The following summer, in collaboration with Dr. H. E. Ives, ${ }^{*}$ the spectral energy distribution of the light from the species Photinus pyralis was obtained by photographic photometry. Last year an attempt was made to obtain photographically the spectral energy distribution of the species Photuris pennsylvanica, which comes earlier in the year. As mentioned elsewhere, $\dagger$ the work was begun too late in the season, and in the course of only a few days this species had disappeared for the year. However, in spite of the lack of sensitiveness of the photographic plates in the red, there was considerable evidence that the light from the Photuris, which to the eye appears a greenish blue, is quite monochromatic, being deficient in the yellow and red rays which are prominent in the light of the Photinus. . Whether the maximum emission is very different in these two genera remained undetermined until this year. The work requires an intimate knowledge of the habits of the various species, the lack of which has been the cause of most of the delays in reaching some conclusion in regard to the various questions under discussion.

One of the foremost problems which now occupies the attention of investigators is the improvement of our methods of illumination. It is recognized that our present methods of light production are of the most primitive type, and yet we seem helpless in the matter. Recognizing our helplessness, we should not hesitate to turn to other animals having photogenic systems which apparently are far more efficient than our own, and try to learn their methods of operation. It may be that in the ultimate analysis the efficiency

*Bull. Bur. Standards, vol. 6, p. 32 I, I909.

†Electrical World, 56, p. Ior2, Oct. 27, r9io. 
of their lighting systems is no higher than our own (but their fuel supply is evidently different from ours) and to learn that much of their secret may be of value.

Aside from this utilitarian question, there are others of equal importance. For example, we know that closely related species of fireflies emit differently colored light, variously described as blue, green, orange, etc. Is this colorvariation a subjective phenomenon, resulting from the variation in color sensibility of the eye with variation in intensity, ${ }^{*}$ or is it an objective reality? If the latter, then what are the laws governing the light emission? It is almost too much to hope to solve this problem in the near future, but it seems possible to settle definitely the question whether or not the light differs in composition and hence is "blue," "green," or "orange," as observed. This knowledge is obtained from the spectral energy curves of the light from various fireflies, to be described presently.

Experimenters have become so accustomed to thinking of the artificial production of light as being accompanied by a large amount of invisible radiation that no experiments would be complete without a repetition of Langley's search for infra-red radiation. Accordingly this question has also been given attention in this paper.

In view of the doubt in many investigators' minds as to whether the color of the light from the firefly is due to a variation in intensity rather than to an actual variation in composition, it seemed worth while to attempt to settle the question by making a thorough study of the light emitted by various species of this insect. Accordingly, the photographic work was continued for about four weeks, during which time $\mathbf{5 2}$ photographic exposures were made, on two spectrometers differing widely in dispersion, the time of exposure varying from 30 seconds to 5 hours. The time consumed in actual photography, in holding the insects on the spectrometer slit, was over $5^{6}$ hours.

The histological data is introduced for clearness in discussing the present work, as well as its bearing upon the whole subject. It permits also a discussion of the plausibility of the functions assigned to certain parts of the photogenic organs as viewed from a physical standpoint and more especially from the optical properties of materials.

While much has already been done on the light of the firefiy, much more remains undone, all of which no doubt will have direct bearing on the manner of light production in animals. Among the important problems awaiting solution are ( $\mathrm{x}$ ) whether, in animals having luminous organs emitting light of different colors, the maxima of emission are different; and (2) whether the maximum emission in any one photogenic cell is the same when the light is emitted from the living animal and when the photogenic material is excited to light emission by an oxidizing agent after the luminous organs have been dried.

Heretofore we have been led to think that "light" must be accompanied by infra-red radiations; and we seem utterly unable to turn away from this idea. 'The various investigations of the firefly have without doubt opened up a new line of thought in regard to the emission of heat and light.

*Knab., Canadian Entomologist, 37, p. 238, 1905. Molisch, Leuchtende Pflanzen, Jena, 1904 . 


\section{HABITS OF THE VARIOUS SPECIES INVESTIGATED.}

At first thought it may seem aside from the main problem to discuss such details, but successful work can be done only after learning the habits of these insects. Not being familiar with the subject at the start, the results given here are the outgrowth of four summers of personal experiences in the field, and it is hoped that they may be useful to others who may be led to undertake similar work. A recent paper by McDermott* is in practical agreement with the experiences herein described.

The insects were caught by means of a net made of white cheesecloth attached to a light wooden handle about $\mathrm{I} .5$ meters long. 'The whitecloth is easily seen and a voided by the insects, butit is more easily handled in the dark.

The habits of the Photuris pennsylvanica are markedly different from the various species of Photinus. The Photuris inhabits damp ground along wooded brooks and rivers, and in the daytime it seems to rest in the trees as well as in the grass, from which it does not emerge untilafter it has become quite dark. It flies high, at great speed, gives a quick flash, and the next moment may be repeating the flash ro to 20 meters away. The color of the light is a rich bluish-green. Because of the darkness, it usually is impossible to see these insects except when they flash. At times, however, when in flight, a faint glow is visible which is easily followed with the net. Late at night they become more quiet and often may be found, flashing, on grass stems and on golden-rod. When struck to the ground, they run about flashing violently (just the opposite from the Photinus) and hence are easily located. Late in the season they seem to rest, without flashing, among the underbrush. Many specimens were caught by beating the brush and taking advantage of their flashing when disturbed and on the ground.

One compensation for the difficulties in catching the Photuris was in finding that they are strong and hardy, not being easily crushed; and that they could be kept for days in large glass beakers ( $12 \times 18 \mathrm{~cm}$.) containing clean moist sod, the top being covered with cheesecloth. They are carnivorous, eating their dead comrades. In captivity they kill and eat the Photinus. The Photinus pyralis are not so easily kept, but are more plentiful and more easily obtained. In the previous work on the latter, they were caught and the photographs made the same night. In the present work, half the night was spent in catching the Photuris, and usually the photographing of the light was done in a dark room on the following day.

In the Photuris the light organs of the female are almost as large as those of the male. 'The females outnumber the males by about $\mathrm{I} 5$ to $\mathrm{I}$, so that one catches but few of the latter.

The Photinus pyralis is plentiful everywhere in this locality. It comes out at dusk, when it can be seen and easily caught. It flies low, hovers about the grass, apparently searching for the female. 'This species is more delicate than the Photuris, is easily injured, and is not so easily kept in captivity. 'The light organ in the female is very small, and from her habit of remaining in the grass, occasionally flashing, and from the fact that the males outnumber the females by about 15 to $\mathrm{I}$, the captured specimens of this species were mostly males. The flash is a long fulmination of yellowish light.

${ }^{*}$ McDermott, Canadian Entomologist, Nov. 1910. 
'The Photinus scintillans and the Photinus consanguineus were found together among shrubbery, in small isolated spots of an acre or less in area. The scintillans is only about 3 to $5 \mathrm{~mm}$. long and is therefore very difficult to handle. On the spectrometer slit it would flash but a few times, when fortunately it would emit a rich glow. A female scintillans was caught while flying about during the daytime. As in the female pyralis, the light organ occupies one-third of the ventral area of the third abdominal segment. Both male and female have the appearance of diminutive pyralis, the color of the wings being more grayish.

The consanguineus is somewhat larger than the scintillans and can be made to flash for a longer time before it begins to glow. Botlı of these species become active early in the evening, but cease their flashing some time before dark. 'The flash is a bcautiful orange-red, which is emitted at long intervals. 'The fewness of these two species and the infrequency of the flash made it difficult to obtain specimens in sufficient number for the requirements of the present work. In work like the present it is necessary to have alarge number of insects to last three hours. Only once was work undertaken (this on the small spectrograph to be described subsequently) with less than a dozen insects, and of this number only two were very active.

\section{COMPOSITION OF THE LIGHT OF FIREFLIES.}

The question of the composition or "color" of the liglit emitted by various species of fireflies is of considerable interest, and may prove of great importance in the theory of radiation. The color of the light may vary according to the species that produces it and from different parts of the body
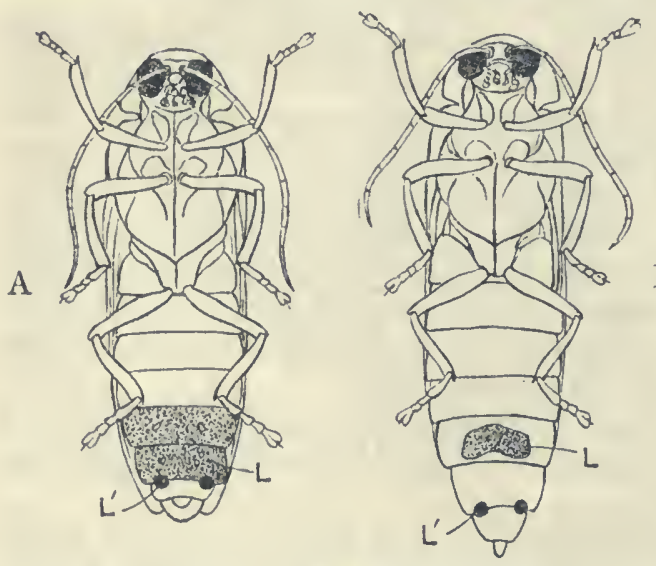

Fig. I.-Photinus pyralis.

$A=$ male. $\quad B=$ female. $L$ and $L^{\prime}=$ luminous organs.

the same animal may emit different-colored light. I'or example, Photinus pyralis has two small light organs, $L^{\prime} L^{\prime}$, Fig. I, on the last abdominal segment which emit light of a decidedly more greenish color than the light emanating from the rest of the luminous organs.

It would be interesting to know whether the maximum emission is different in the two luminous organs or whether this greenish color in $L^{\prime} L^{\prime}$ is simply a question of intensity. In the Photinus pyralis it appears to bealowintensity effect. Whether there is an actual variation in the composition of the light emitted by any one luminous organ is of considerable interest, as this would show that not only the act of emitting the light, but also the composition of the light, is under control of the insect. Whether there is such a variation in the composition, subject to the control of the insect, would be difficult to establish. 
It is evident, from visual observations, that the range of variation in color of the light of any one species, whether or not it is under control, must be very limited in extent. Occasionally, however, one finds specimens of a given species in which the light seems to differ from the accustomed color. This is especially true of the Photinus consanguineus and scintillans. For example, while photographing the light from Photinus consanguineus a speeimen was found in which the flash appeared a deeper reddish-yellow than that usually observed. To the eye it appeared as though the photogenic material extended into the adjacent dark segment, and as though the color of the light emanating from the line of intersection of the second luminous segment with the adjoining dark segment was of a more reddish tinge than the light coming from the other parts of the luminous segments. 'This was probably caused by absorption of the yellow and blue light in passing through the slightly brownish integument joining the segments. 'The extension of the luminous organs under the dark segments would explain the reddish light sometimes observed in insects. Several other specimens were observed in which, while plotographing, the light changed from an orange to a decidedly reddish-yellow hue. The illumination was so weak that it was extremely difficult to keep the insects in place on the spectrometer slit, and it is therefore evident that this change in color was not due to the physiological effeet of low intensity on the retina; for in that case the light should have appeared greenish.

As so much importance has been attached to the physiological effect of lights of different intensities upon the retina, notes were made of the appearance of the light emitted by various species. After sitting in a dark room from two to four hours, in which fireflies of all degress of activity were handled, it was an easy matter to study this effect. The observations extend over several weeks and are in complete agreement. 'They show that for the same genus at low intensities the light is more bluish than at high intensities, which is the physiological phenomenon. Examined side by side, after being in darkness for three hours, the glow of Photinus pyralis appeared more yellow than that of Photuris pennsylvanica, and the flash of the latter appeared bluer than the glow of the former. This evidently can not be explained on the basis of physiological optics. The glow from Photinus consanguineus was at all times greenish to yellowish, while the flash was a reddish-yellow. 'This evidently is the physiological effect of variation in intensity. However, when we compare the latter with Photinus pyralis and find that its light is reddish-yellow in spite of the fact that it is barely sufficient to illuminate the spectrometer slit, while the light of Photinus pyralis is greenish-yellow and is of sufficient intensity to read the time on a small watch dial, it is evident that there is an actual difference in the light emitted by the various genera and species of fireflies.

After one has done field work for several summers, has handled hundreds of these insects, and has observed the viciousness with which the Photuris pennsylvanica, in captivity, kill and devour the smaller species, e. g., pyralis and scintillans, one concludes that, if for no other purpose, the difference in the color of the light is useful as a distinguishing mark of the different species. 
In photogenic bacteria the color of the light* appears to depend upon the environment and the culture medium; and in any one medium the light is described as silvery white, bluish, greenish, or tinged with orange, depending upon the species. Among the mushrooms there are similar variations, one species emitting a bluish, another a greenish, and still others a whitish light.

In addition to the fireflies investigated, through the kindness of Mr. F. A. McDermott (then connected with the Hygienic Laboratory of the U.S. Marine Hospital Service), an opportunity was granted to examine a large glow-worm (female of Phengodes laticollis) which along its sides emitted (in spots of about $1 \mathrm{~mm}$. diameter) a rich greenish light; also an Elater (Pyrophorus noclilucus) from Cuba, of which the cye-spots (I mm. diameter) showed a weak greenish glow; and a culture of photogenic bacteria (Pseudomonas lucifer a Molisch), which appeared a rich grcen in color though weak in intensity. Because of the weakness of the light, which would have required an exposure of eight to ten hours, using the large spectrograph, no attempts were made to photograph the light of these animals. From the data to be discussed presently, it will be possible to give an estimate of the quality of the light emitted by these animals without subjecting it to rigid examination.

Some insects are described as emitting a "red light." If this is the "cardinal" or the "scarlet" one usually thinks of when reading such a description, the color must be very remarkable and deserves investigation. First of all, it would be desirable to know whether the description is correct and whether the "red" may not in reality be the "orange red" observed in Photinus scintillans.

Tests have beell madet to decide on the color of the light cmitted by fireflies by examining them in the light of a kerosene or an incandescent lamp. 'The writer has tried the same experiment and concluded that such observations are meaningless, for the reason that the light observed is composed of that emitted by the firefly and of that emitted by the lamp, which, by internal reflection in the photogenic cells, is returned to the eye. The resultant color of the combination can hardly be considered a criterion for judging the color of the (unmixed) light emitted by the insect.

The popular notion is that the maximum emission of the sun and the maximum color sensitivity of the eye coincide; and that this is the result of evolution of the eye so as to utilize the sunlight to the best advantage. In the same manner comments have been made on the supposed coincidence of the luminosity curve of the eye and the luminosity of fireflies. In the attempt to harmonize all phenomena, the fact is overlooked that the structure of the (compound) eye of an insect is entirely different from the human eye. It remains to be shown that the insect eye is sensitive to color with a maximum of sensibility such as obtains in the human eye.

*Molisch, Leuchtende Pflanzen, Jena, 1904.

†Knab, Canadian Entomologist, 37, p. 238, 1905. 


\section{THE FUNCTION OF THE LIGHT EMITTED BY LIVING ORGANISMS.}

Various explanations have been offered to account for the presence of the light emitted by living organisms. For example, the light from fungi would serve as an illuminant to worms and insects.*

The light emitted by insects, or fishes, would serve as a bait to attract prey; to illuminate the way; to blind its prey and thus prevent its escape; to blind its enemies and thus serve as a defense; to serve as an adornment in more highly organized forms; or, most plausible of all, to serve as signals between male and female of the same species. $\dagger$

The light of the firefly is evidently intended as a means of attracting one another. For example, during the work of photographing the light of the firefly, on at least three different occasions fireflies, which had escaped into the room and were flying about flashing, came to where an insect was being held upon the spectrometer slit, and were caught. Further evidence was accidentally found in the field work. The insects were caught and placed in test tubes. Later they were transferred to a large wide-mouthed bottle covered with cheesecloth. Leaving such a bottle in the field occasionally attracted Photuris pennsylvanica. On returning to the laboratory, carrying the bottle of insects, on two occasions Photuris alighted on the writer's shoulder and were caught. In view of the difficulties usually encountered in catching this species, these experiences can hardly be considered accidental. The habit of the female Photimus pyralis remaining in the grass, occasionally flasling, and of the male pyralis hovering about the ground, rising up and down and flashing, is further evidence that the light is useful as an attraction for these insects, where in others the same end is accomplished by the emission of sounds. This habit of rising a few feet above the ground, remaining stationary and fluttering the wings, is to be observed also in the large yellow-winged grasshoppers.

To the writer most of these explanations seem far-fetched. For example, if the Photuris desired to hide when molested, why does it run about the ground flashing violently, instead of dropping to the ground on the slightest provocation and disappearing without a flash, which is the habit of the various species of Photimus. Again, one species of firefly in the larval state has photogenic organs, but in the adult state has none. In some localities the mating of the glow-worm (Phengodes) is said to occur in the daytime; hence the liglit emitted can not be of great service in mating for that purpose.

*Pütter, Leuchtende Organismen, Zeitschr. f. Allg. Physiol., 5, 1905.

†Mangold, "Die Produktion von Licht," Winterstein's Handb. der Vergleich. Physiologie, Band 3, I9I I. 


\section{HISTOLOGY OF THE. LIGHT ORGANS.}

For clearness in understanding and ease in describing the thermal and other measurements given on a subsequent page, the general topography of the ventral side of a firefly (Photinus pyralis) is given in Fig. I. 'The dark areas, $L$, represent the regions of the luminous organs. It will be noticed that in the male the luminous region includes the whole of two segments (the second and third from the end), while in the female only about a third of the third segment is luminous. In Photinus pyralis there are two additional points of light, $L^{\prime} L^{\prime}$, which are of a more greenish hue than the light emitted from the rest of the body. 'These points of light are of interest in connection with the temperature measurements to be discussed presently. In the male Photuris pennsylvanica the luminous organs are situated as in Fig. $x$. In the female the dark area, illustrated in Fig. $I$, is expanded so that it occupies about three-fourths of eacll of the two segments (the second and third from the end). Hence the female is almost as luminous as the male.

In Fig. 2 is given a transverse section through the entire abdomen of the firefly Photinus marginellus, studied by Townsend, ${ }^{*}$ and in Fig. 3 is given a detailed view of the general structure of the luminous organ. Irig. 4 gives illustrations of transverse sections of Photuris pennsylvanica and Photinus pyralis re-

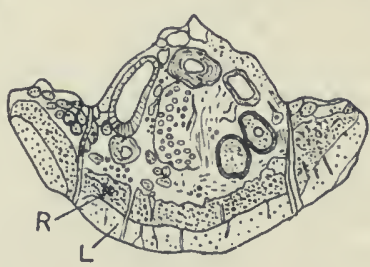

Fig. 2 .

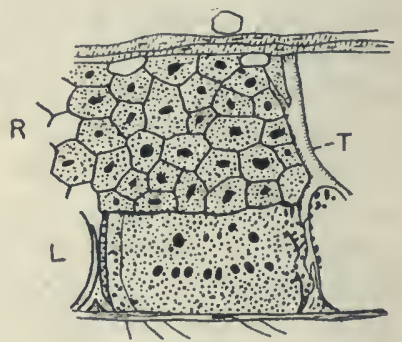

Fig. 3 .

$L=$ luminous tissue, $R=$ reflecting layer. $T=$ trachea. cently studied by McDermott and Cranc. $\dagger$

In all these illustrations, $L$ is the photogenic tissue, $P$ is the pigment layer, and $R$ is the so-called "reflecting layer," the properties of which will be mentioned presently. From a physical standpoint these comparisons are of great interest, because the structure of the photogenic organs is practically the same in all three insects, although the Photuris is a distinct genus, widely separated from the Photinus in the scale of development. Evidently the structure of the luminous organs has nothing to do with the great difference in the color of the light emitted by these two insects.

A further illustration of the great similarity of the essential parts of the photogenic organs in different animals is given in Fig. 5, which shows a transverse section $\ddagger$ through a luminous organ situated on the ventral side of a marine fish, Maurolicus pennanti. Here again we see photogenic material, $d . K$., backed by the so-called "reflecting layer, $i . R$. 'The whole light organ is inclosed with a layer of black pigment, $P$, on the inner wall of which

*'Townsend, American Naturalist, 38, p. $127,1904$.

$\dagger$ McDermott and Crane, Amer. Naturalist, 45, p. 306, I 91 1.

†Mangold, Winterstein's Handb. der Vergleich. Physiologie, vol. 3, 19 I I. 
is a layer of highly insoluble material, which, as already mentioned, is called the "reflecting layer." The light is generated in the glandular material, the "drüsenkorper," $d . K$., and passes through the funnel-shaped opening, finally emerging through the lens, $l$, into the air.

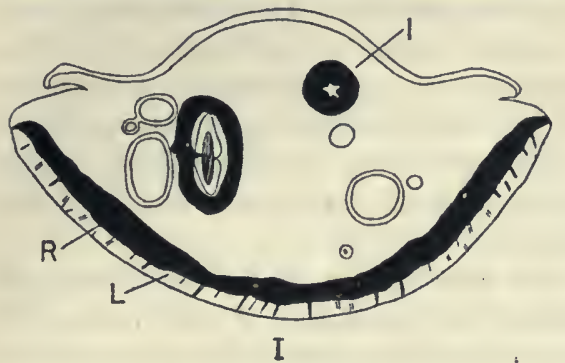

I. Section of Photuris pennsylvanica.

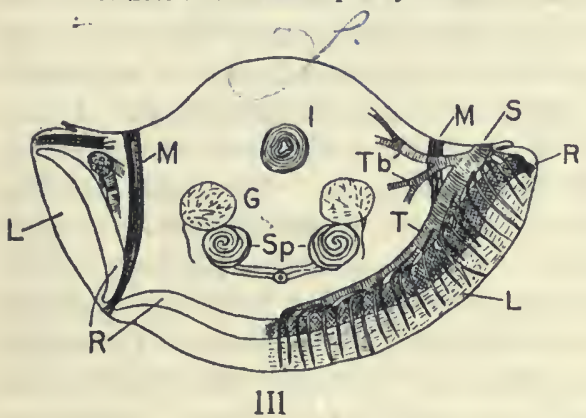

Fig. 4 .

'This description seems a little fantastic, for optically the system is extremely inefficient. 'The low reflecting power which must obtain in the so-called "reflecting layer" and the roundabout way for the light to reach

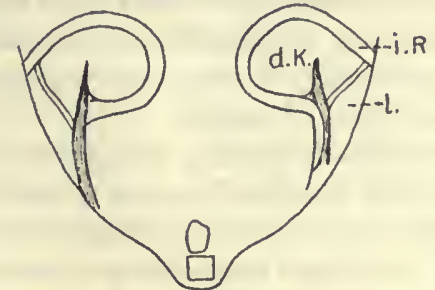

A

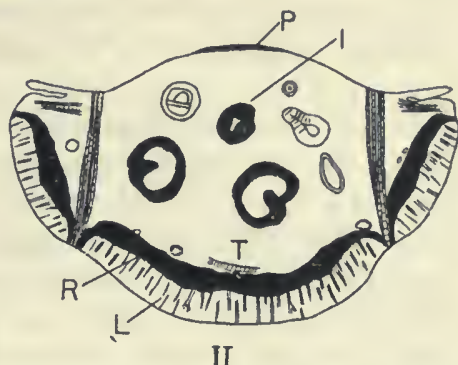

If. Section of Photinus pyralis. $P=$ pigment.

III. Trausverse section of Photinus pyralis (diagrammatic).

The right-hand half slows the arrangement and distribution of the trachex, while the leit-hand half shows the modification of the luminous tissue at the point of attachment of the breathing muscles.

$G$, testes; $I$, intestine; $L$, true photogenic tissue $R$, reflecting layer; $S$, spiracle or stigmatum $S p$, spiral organs (function uncertain); $T$ main trachex to photogenic organ; $T b$, main respiratory tracheæ: $M$, muscle fibers. 
searchlight, which projects the light in a fixed direction. 'The pocket sliape of the photogenic cell might be brought about by gravity. 'The refractive index of the material composing the so-called "reflecting layer" can not differ greatly from the water and other constituents in the photogenic cell and hence there can not be a distinct reflecting surface. As stated elsewhere, a careful examination of a firefly, Photinus pyralis, shows that the whole dorsal region of the abdominal segments containing the photogenic material, except the narrow median line $P$, Fig. 4 , II, which is filled witl dark pigment, is aglow (in fact flashes strongly) when the insect emits its flash. 'This could not occur if the so-called "reflecting layer" performed, to any appreciable extent, the function attributed to it.

Althougl from the earliest times the phenomena of light emission by animals, "biological light," has attracted the attention of observers, only within the past century has any serious investigation been made of the photogenic organs. According to 'Townsend (1. c.) there now seems to be a general agreement among experimenters that in the male lampyrids the photogenic organs are composed of two well-defined layers: the dorsal, chalky, opaque layer, $R$, and the ventral or true photogenic layer, $L$ (see Figs. I to 4). 'The latter is composed of two distinct elements: the tracheal structures and the intermediate areas of parenchyma. The main trachere (see illustration, Fig. 4, III) of the photogenic segments send vertical branches down through the light organs. 'l'hese tracheæ ( $T$, Figs. 3 and 4$)$ appear to connect with the main breathing system; and from this evidence some hold to the belief that the light is produced by oxidation. "The entire system suggests that the air is drawn in through the breathing tracheæ, and forced through the fine passages in the true photogenic tissue, where the oxygen of the air is consumed in a biologic oxidation."'*

While this seems a highly plausible explanation, the details as to the manner in which the light production is regulated do not appear so simple. For, if the data on the temperature of the luminous segments, presented on a subsequent page, has any significance, the oxidation seems a continuous process, while the light production (the intense flashes) is controlled at will. One peculiarity in the control of the light emission is the manner in which the flashes may be emitted in one segment or in one small part of the luminous segment while all the rest of the luminous organs are emitting a bright glow. A slight pressure on the luminous segment apparently paralyzes that region and it begins to emit a strong glow, while at intervals the usual flashes are emitted from the uninjured, non-glowing parts.

'The dorsal layer ( $R$, Fig. 3 ) is composed of fairly regular polygonal cells, filled with white crystalline material, which is supposed to be urate salts (either guanine or ammonium urate, or both). 'This is the so-called "reflecting layer," the idea to be conveyed being that this material is present to shield the central nervous system, lying directly above it, from the light produced in the layer below it, and more especially to act as a reflector to increase the illumination in the direction desired. From an optical standpoint this does not appear very convincing; for the optical properties of a granular mass of material such as described, and of the thickness indicated, would have a low reflecting power and would be but little more than a dif-

${ }^{*}$ MeDermott and Crane, Amer. Naturalist, 45, p. 306, 191 r. 
fusing screen transmitting almost as much as it reflects, and causing the glow which is visible throughout the whole abdominal region when the flash occurs. An examination of the dorsal side of the abdomen shows that only along the median line, where the integument is dark, is the light absorbed. Evidently the absorption is caused by the dark pigment. 'The rest of the abdomen is all aglow during the flash. This could not occur if the "reflecting layer" were efficient.

'The more radical views of Dubois* may be given equal weight. He lias found the eggs of Pyrophorus noctilucus to be luminous even before they were laid, so that the light appears to be transmitted in unbroken continuity from one generation to the next. By following the development of the light organs through all the different stages occurring from the beginning of segmentation of the egg to the emerging of the adult insect, he has reached the conclusion that the photogenic tissue in the light organs is derived directly from the underlying hypodermis, and that in the development of the light organs a transformation takes place in the protoplasm of the cells, the older cells toward the upper surface of the light organs becoming filled with opaque, chalky granules forming the aforesaid "reflecting layer."

Dubois has shown that the mollusk Pholas dactylus produces photogenic matter in the form of a liquid which remains luminous after filtering. The photogenic liquid contains fine granulations that give it a cloudy appearance. These granulations are of a colloidal nature which is lost in passing into the crystalline, when the light emission ceases. The Orya barbarica of Algeria secretes a luminous fluid which, under the microscope, shows photogenic granulations that are said to become magnificent crystals during the light enission. The theory of Dubois is that the light is produced as the result of the action of an "oxidase" (oxidizing agent) upon another substance, also of unknown composition. According to Townsend, the view generally accepted is that the light results from the oxidation of a substance produced by the metabolism of the light organs. The nature of the substance is unknown. That its photogenic property is independent of the life of the cell is proven by the fact that when the organs are dried and reduced to a powder the light reappears under the influence of air and moisture. $\dagger$

The thickness of the "reflecting layer" is about the same in both species, but in the Photuris the layer of true photogenic tissue (Fig. $4, L$ ) is much thinner than in the Photinus. It will be shown presently that the light from the Photinus is much richer in orange-red radiation than obtains in the Photuris, which emits bluish light. Whether this is owing to a variation in the thickness of the radiating layer is a question requiring further study.

On a subsequent page it will be shown that after a firefly has done a certain amount of flashing it suddenly ceases flashing and (if the photogenic organs do not at once begin to emit a bright glow which soon decreases in intensity, when the insect succumbs) it is useless afterwards. It would be desirable to learn whether the insect stores a certain amount of energy or "fuel," when in the larval state, which is consumed in flashing when in the

*Dubois, Compt. rend.,'Ass'n franc. avanc. Sci., Sess. 22, p. 298; Leçons de Physiologie $P$. générale et comparée, Paris, 1908.

†In this connection see Bongardt, Zeitschr. f. Wissensch. Zoöl., 75, p. I, 1903. Kastlc and McDermott, Amer. Jour. Physiology, 27, p. 122, 1910. 
adult state. It would also be interesting to examine sections of Photuris after the insect has flashed for an hour and a half or longer, as described clsewhere, and of a similar specimen which has not undergone such a period of flashing, to see whether the "reflecting layer" is markedly different in the two samples. Of course numerous examples of each (of the same age) would have to be examined to obtain an average value.

\section{METHODS OF INVESTIGATION OF THE LIGHT EMITTED.}

As with other sources of radiation, the best metlod of investigating the composition of the light of the fircfly appeared to be one involving the determination of the spectral energy curve. Because of the weakness and intermittence of the radiation it is not possible to use a bolometer or a spectrophotometer, and the only satisfactory method is the one involving photography. While this seems to be an indirect method to obtain a spectral energy curve, it will be noticed presently that it is not so cumbersome as it appears. 'The photographic plate, being integrative in its action, is well adapted to the investigation of weak and intermittent sources, but it must be of a special kind which is sensitive to all parts of the visible spectrum. 'The nearest approach to this condition is the Wratten and Wainwright "Panchromatic" plate, which is sensitive, in a variable degree, to all the frequencies from the ultra-violet far into the red. The method is really a species of spectrophotographic photometry in which the light of the firefly and that of the standard source are photographed, after which the "densities" of the negatives are compared.

In ordinary spectrophotometry one compares intensities. In the photographic method the effects of these intensities on the photographic plate are compared, the element of time being the unit of measure and the effect of a given intensity upon the photographic plate being taken proportional to the time of exposure. This, of course, is not true for long exposures. For a limited range the density of the plate is proportional to the time of exposure; beyond this range saturation begins and, still farther away, reversal takes place. It is therefore necessary to determine the exposure equivalent of each density measured; that is to say, the "characteristic curve" of the plate must be determined. This is accomplished by making a series of exposures of known relationship of a standard source in which the densities cover the same range as those obtained on the unknown source, e.g., the fireflies. Such a series of exposures are shown in Plate I, $A$, the standard source being a carbon glow-lamp operated on 4 watts per candle. 'Thelamp was placed at a fixed distance from the spectrograph slit, which was covered with a ground-glass plate, the voltage was kept constant, and a series of exposures was made corresponding to $2,4,6,8$, 10, 12, 20, 30,60, 120, and 240 seconds. For densities on the firefly negatives, in which there were no corresponding density measurements on the glow-lamp, the characteristic curve of the latter was drawn for the particular wave-length in question, and the firefly density value was determined by interpolation.

Since the energy value, "mechanical equivalent," is not the same for all rays, it is necessary to know the spectral energy distribution of the carbon glow-lamp. This was determined anew for the present research by means of a large vacuum spectrobolometer, fluorite prism, and mirror spectrometer. 
The photographic plates were imported fresh from the factory about a month before work was begun. It is, of course, impossible to obtain all the .glow-lamp and firefly exposures upon one plate, and since they were all from the same batch as sensitized in the factory it was assumed that all the plates have the same "characteristic curves" as those obtained from the spectrum of the carbon lamp photographed upon one plate. That this assumption was permissible is shown by the excellent agreement of the spectral energy curves of the light of the firefly as obtained from different plates taken from the same box and from different boxes.

More important than the difference in the plates is the question of development. All plates were developed, under identically the same conditions, by time, in complete darkness, the developer and fixing bath being kept cool to prevent the softening of the gelatin. 'The negatives should therefore be comparable without all the exposures being made on one plate. In fact, when using the large spectrograph, there was usually a long and a short exposure of a given species of firefly, from which it was possible to obtain the complete energy curve from one plate. Experience showed that, although the photographing was done in a well-darkened room, when the plate was in the holder for from 4 to 6 hours it became "fogged," and hence, when photographs were taken during the daytime, no attempt was made to obtain more than two negatives on one plate. Such plates, when developed, were entirely free from "fog." No risks were taken in developing the plates, fresh developer (metol-guinol) being made up each time. The agreement of the photometric curves of the light of the same insect, obtained from different plates, indicates that but little would have been gained by attempting to photograph different species on the same plate.

In the vicinity of the Bureau of Standards, District of Columbia, the flight of the Photuris occurred the first week in June, and no Photinus pyralis could be found until the last week in June, when but few examples of Photuris were to be seen. However, by bringing Photinus pyralis from some distance* (in a different part of the city of Washington some 3 miles away, where the pyralis appeared in the middle of June), it was possible to obtain the short-time exposures of various species on the same plate (Plate $1, D$ ), using the small spectrograph to be described presently.

The proper timing of the exposures was found impossible, other than the rough estimate of exposing the plate to the pyralis from $\mathrm{r}$ to 2 hours, and about four times as long to obtain the same impression from the Photuris. An excellent example of the uncertainty in the matter is shown in Plate $I$, $B$, spectra 4 and 7 . The former was obtained in an hour and the latter in $3 \frac{1}{2}$ hours. It was intended to have the two negatives widely different in densities, but they are identical in density (see Fig. 7, "plate 5:27:' I I"). On one occasion a $5^{\frac{1}{2}}$-hour exposure did not give as dense a negative as the one recorded in Fig. 7 , "plate $5: 26:$ ' 11 ." This is owing to the fact that after being in captivity for a few days the activity of the insect is decreased and its flash does not seem to be so intense.

Two spectrographs were used in obtaining the photographs of the firefly light. The one was a large quartz-lens instrument having a focal length of

*Especial acknowledgment is due to Mr. U. F. Rosen for his faithfulness in catching these specimens, and for valuable aid throughout this season's work. 
I meter. When used with a light flint-glass prism the dispersion in the yellow was sufficient to separate the yellow mercury by $0.5 \mathrm{~mm}$., the total length of the spectrum between the green $(\lambda=0.50$ I $\mu)$ and the red $(\lambda=0.667 \mu)$ helium lines being $37 \mathrm{~mm}$. The firefly light falls within this same region. A small spectrograph, of triple achromatic lenses $6 \mathrm{~cm}$. diameter and 18 $\mathrm{cm}$. focal length, which had a much greater light-gathering power, was used in photographing the weak radiations in the red. The same prism (of light flint-glass) was used on both instruments. In the large spectrograph the slit opening was $0.75 \mathrm{~mm}$. and in the small instrument it was $0.4 \mathrm{~mm}$. The collimator slit was covered with a small piece of white cardboard containing an opening $5 \mathrm{~mm}$. high and $2 \mathrm{~mm}$. wide, which enabled the operator to center the fireflies over the slit, by means of their own light; for, as already mentioned, the photograpling was done in a completely darkened room.

'The method of procedure consisted in holding the insects in the fingers, one or two at a time, over the spectrographic slit. The constant struggle of the insect to get away caused it to flash more frequently than is its accustomed rate. If it became quiet and ceased to flash, a movement of the fingers, or allowing the insect to move about, increased the frequency of the flashing. Frequent flashing is an important item when it comes to making exposures to weak sources like the firefly, requiring from I to 5 hours to obtain a satisfactory negative.

In the small spectrograph only from I to 60 minutes were required to obtain a uniformly exposed, dense negative. On the small apparatus a single flash from the Photinus pyralis was sufficient to cause a streak across the plate (see Plate I, $D, \mathrm{~V}_{\mathrm{I}} 2$; and VII 5,6 , and 8), and in order to obtain a uniformly exposed negative, the slit was covered with a piece of ground glass. In Plate $\mathrm{I}, D, \mathrm{~V} 2$ the negative was obtained in 2 minutes from $5^{\circ}$ flashes of pyralis through ground glass; III 2 was similarly obtained from 8 flashes; III 5 from 20 flashes; III 6 from 35 flashes; III 7 from 60 flashes; III 8 from 5 flashes; and III 9 from 100 flashes or about 4 minutes. On the other hand, the negative directly below this one, III Io, required 30 minutes exposure (without glass) to a male Photuris pennsylvanica which flashed at the rate of about roo times per minute.

As indicated elsewhere, the longer time required for exposure to the Photuris is not because of the lack of intensity, but because of the shorter (as compared with pyralis) duration of the flash. Although the luminous organs in the two species are different, those of the Photuris being the smaller, the area covered on the spectrograph slit is not markedly different in the two insects.

On the spectrometer slit, the Photinus scintillans and consanguineus could be made to flash about 4 to 5 times per minute. 'The Photinus pyralis flashed about 20 times per minute when at its best, but the flash lasts longer and therefore (aside from its greater volume) has a greater effect on the plate than the flash of the Photuris pennsylvanica. In the Pholuris pennsylvanica the flash, accompanied by a "twinkling effect," often occurs at the rate of 2 to 3 times per second, which in some male specimens was sometimes continued for an hour or more with but few interruptions.

Only a few specimens of Photuris glowed vigorously during the photographing. The Photinus pyralis easily tires of flashing and then emits a 
strong glow which usually is the signal of the end of its usefulness. If, however, it is placed in an inclosure and allowed to rest, it often resumes the flashing. As stated elsewhere, the flashing is under the control of the insect, unless injured or overexerted when the luminous organs begin to glow. This glow may be in only one segment. Sometimes the glow extends over one whole segment and part of the other segment. The non-glowing part of the latter will then be found to emit its flash as usual; and in one case it was found that this local flashing continued for about ro minutes. The application of a slight pressure caused a continuous glow to be emitted also from this part.

The Photinus scintillans is so small that it is handled with great difficulty. Its flashes are few, but it emits a strong glow. Only one plotograph was made, Plate $1, D, I_{14}$, in which the light was entirely of the scintillans. In Plate I, D, I I , a few glowing scintillans were used, the negative being finished with consanguineus.

In order to make certain that at least some of the negatives would prove suitable for demonstrating the great difference in the light emissivity, the method adopted was to take one or two exposures of the Photuris and to fill in the rest of the plate with the light of the Photinus pyralis, which required less time to obtain an exposure. In this manner it was possible to obtain negatives of the pyralis which were both more and less dense than the photographs of the Photuris. From these photographs it was easy to see that the light of the Photuris does not extend so far into the red as does the Photimus. This is well illustrated in Plate $\mathrm{r}, B_{4}$ and 7 (Photuris) and 5 and 6 (Photinus). If it were simply a question of "density" or time of exposure, then 5 should have extended farther into the blue than 4 , just as it does in the red. This is better illustrated in Fig. 7, "plate 6:19:' I I" and "plate 5:27:' I I," which gives the photometric densities of Plate $1, B 5$ and 6 , and 4 and 7 , respectively. Here it is shown that, for the same density in the blue, the Photinus shows a far greater abundance of radiation in the red than obtains in the Photuris. In Plate I, D, the scintillans, I I4, and the pennsylvanica, I I3, are of the same density (by actual measurement) in the yellow, yet the former lies the farther toward the red. Similarly, Plate $1, D$, the pyralis, II 7 and 8 , pennsylvanica, II 9 and 10 , and consanguineus, II $1 \mathrm{I}$, have closely the same density in the yellow; and a mere visual inspection shows that the maximum of the radiation of the pennsylvanica lies farther toward the blue than obtains in the other species. All these negatives show that the less dense Photuris extends farther toward the violet than does a more dense Photinus, which would not be possible if the light of the two species had the same composition and differed merely in intensity. So much emphasis is placed upon this point for the reason that, among those with whom the writer has discussed the matter, the predominating opinion is that the whole effect upon the eye is, and should be, the result of a difference in intensity. 


\section{SPECTRAL ENERGY CURVES OF THE LIGHT EMITTED BY VARIOUS SPECIES OF FIREFLIES.}

The photographs just discussed show that some fireflies emit light which is much richer in the red rays than obtains in the light of other species. It is important to know whether this is due simply to a difference in the shape of the spectral energy curve, or whether the maximum emission is different in the various species. 'To obtain this information it is necessary to eliminate the unequal sensitiveness of the plate for different wave-lengths, and also the change in the density exposure relationship for different colors. This is accomplished by finding the "densities" or "blackening" of the photographic plate, for which purpose a Martens polarization photometer was employed. The photometer was substituted for one of the microscopes on a small comparator, as shown diagrammatically in Fig. 6. A beam of light from the standard lamp, $I$, passed directly into the photometer, $Q$. A second beam of light, on reflection from the mirror, $M$, passed through plate, $N$, to be examined, through the slit, $R$, and into the photometer.

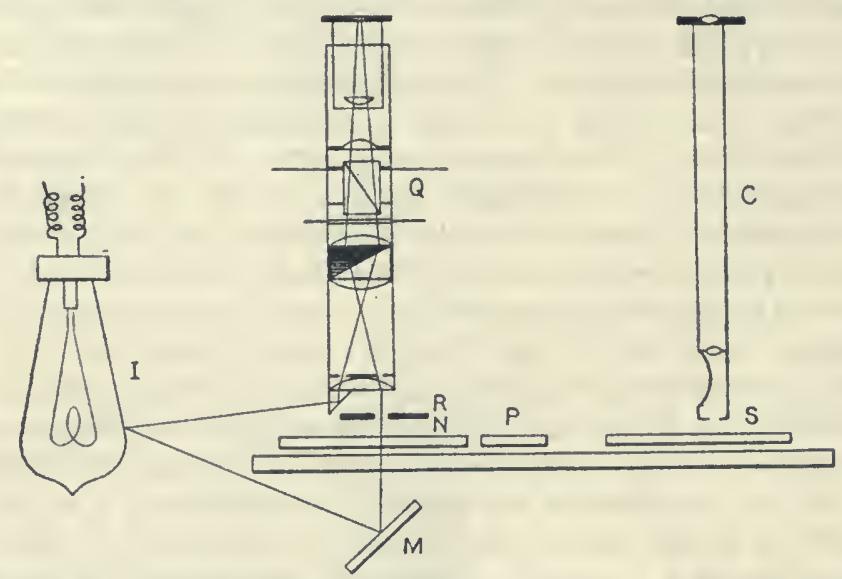

Fig. 6.- Side view of photometer used in measuring densities of the photographic plates.

Although this was not absolutely necessary, a standard plate, $P$, was kept on the comparator, for reference in case of accident to the adjustments. The slit, $R$, was placed as close as possible (about $0.2 \mathrm{~mm}$.) to the plate, $N$, so as to take in the width desired and no more. 'The width of the slit, $R$, was $0.5 \mathrm{~mm}$. for the small spectrometer and $\mathrm{mm}$. for the large instrument. Lengthwise on the negative, $N$, was placed a strip of black paper with a slit in it, which was somewhat longer than the photograph of the spectrum. This slit was $1.5 \mathrm{~mm}$. wide for the large spectrometer, and $\mathrm{I} \mathrm{mm}$. wide for the smaller instrument. The microscope and scale, $S$, were used to make settings on the different parts of the negative. In this manner, for the negaatives obtained with the large spectrograph, strips $1.5 \mathrm{~mm}$. high and $\mathrm{r} \mathrm{mm}$. long were compared against the clear unexposed plate. In the same manner, for the negatives obtained with the small spectrograph, strips I to $1.2 \mathrm{~mm}$. high and $0.5 \mathrm{~mm}$. wide were photometered. One of the helium lines, illustrated in Plate I, $B$, I was used as a reference standard and the points of measurement were the same on all the plates. 
The "densities," i. e., the amount of light absorbed, were than plotted to a scale as indicated in Fig. 7. In this illustration the heavy lines ( $\mathrm{x}-\mathrm{x}$, - - ) give the effect of the light of Photuris pennsylvanica, of Photinus pyralis (๑- $-\odot+-\infty)$ and of the carbon glow-lamp $\left(----, 4^{\prime \prime}, 8^{\prime \prime}\right.$, etc.) as recorded on the large spectrograph negatives. In the same manner, Fig. 8 shows several density curves of Photuris pennsylvanica (•————),

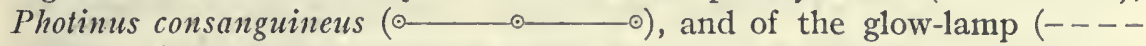
$------)$, as measured on the negatives obtained with the small spectrograph. In all cases the Photinus density curves extend farther into the red. Evidently the time of exposure, i. e., effect on the photographic plate, has nothing to do witl the question of obtaining an impression in the red. In other words, the lack of "density" in the negative of the red end of the spectrum is owing to a deficiency in red rays, in the light emitted by the Photuris; it is not a lack of intensity of the emitted light.

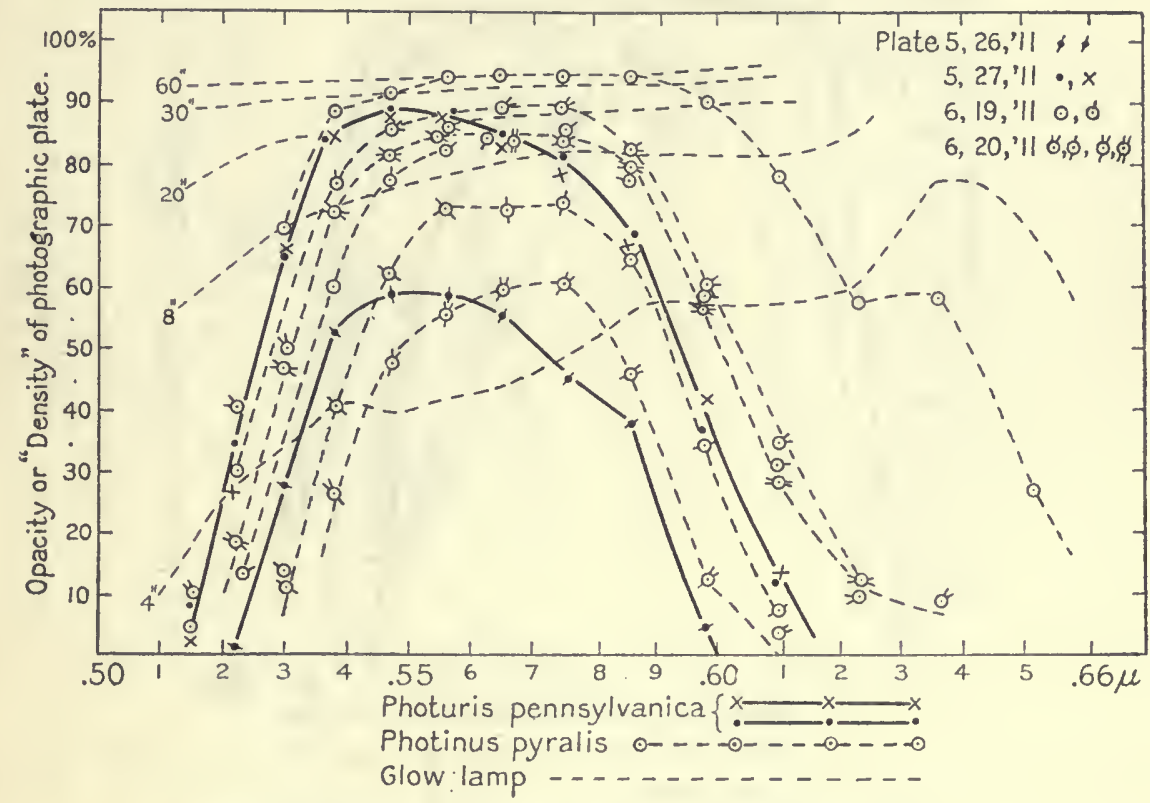

Fig. 7.-Spectrum density curves of photographic plates. The two lieavy continuous lines are for Pholuris pennsylvanica.

This illustration in itself is an ample demonstration that the light of the Photinus pyralis is much richer in red and yellow rays than is the Photuris; for the curves intersect, and all those of the Photimus, whatever the density, lie to the right of those of the Photuris of equal density. But we can go a step farther and eliminate the inequalities of sensitiveness for different wave-lengths, by comparing the densities of the negatives. It is assumed that the density, or the effect of the light upon the photographic plate, is proportional to the time of exposure. This is of course not true for very long exposures, and hence the highest parts of the curves are not used in this work. For convenience the 4 seconds density curve of the glow-lamp was taken as the unit of comparison. Hence the 8 seconds density curve represents 2 units, the 12 seconds density curve represents 3 units, etc. 
'Turning now to the firefly curves we see that the upper, heavy density curve of Photuris pennsylvanica intersects the 4 seconds density curve of the glow-lamp at $0.520 \mu$ and at $0.592 \mu$; i. e., at these two points the two curves have the same density, which in magnitude on our arbitrary scale is I unit. At $0.532 \mu$ and at $0.572 \mu$ this same Photuris curve intersects the 8 seconds density curve of the glow-lamp and hence, on our arbitrary scale, its photometric value at these two points is two units. At the intersections with the 20 seconds density curve of the glow-lamp, the photometric value is 5 units; and so on. These photometric values, I, 2, 5, etc., or "ratio of densities," are plotted to scale as ordinates in Fig. 9, and the corresponding wavelengths as abscissæ. The dotted curve in this illustration is plotted from Langley's photometric values of Pyrophorus noctilucus. The firefly curves

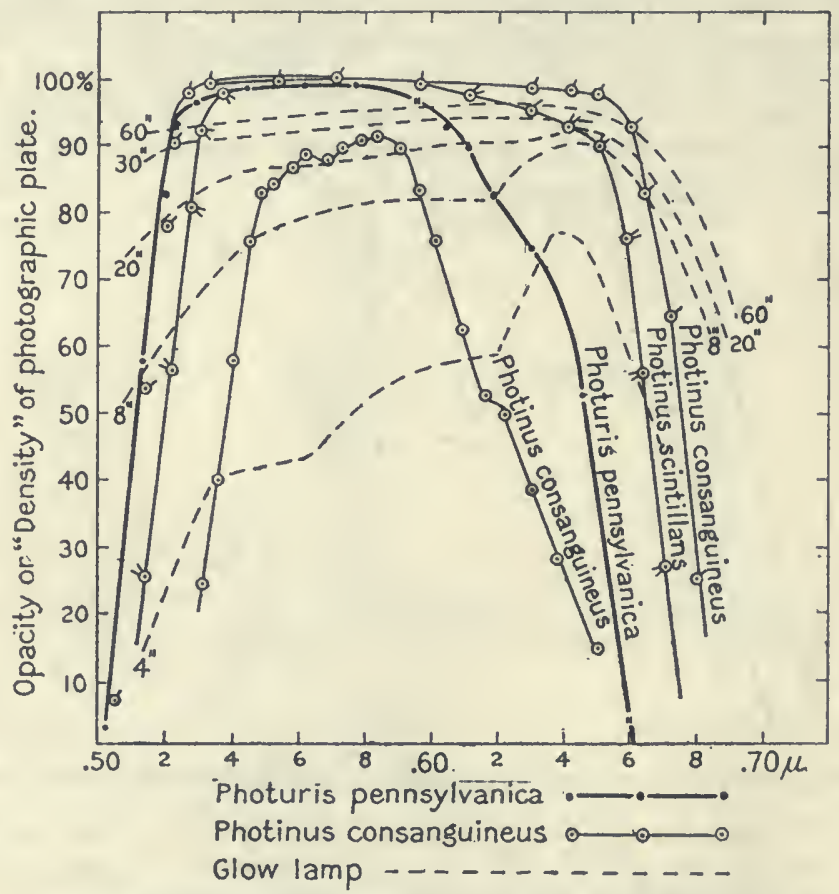

FIG. 8.-Spectrum density curves of photographic plates.

have now been compared against a standard source, and their maxima are found to be entirely different. It is of interest to note that the glow-worm (larva of the Photuris pennsylvanica) has its maximum at practically the same place as has the adult insect.

In these curves, Fig. 9 , the various circles $\left(\odot, \odot, \odot^{\prime}\right.$ etc.) indicate that the resultant curve is the composite of numerous "ratio of densities" curves (see Fig. 7), obtained by multiplying each "ratio of density" curve by a suitablefactor. The photographic plate is very sensitive in the region of $0.590 \mu$ and it is difficult to eliminate this effect in the firefly curves. The hump in the curve of the light from the glow-worm and of Photinus consanguineus at $0.59 \mu$ is therefore not considered of real significance. 'The curves of these 
two samiples were obtained from the photographs taken with the small spectrograph, Fig. 8. Knowing the distribution of energy in the spectrum of the glow-lamp given in Fig. 1o, it is possible to determine the spectral energy distribution of the firefly by multiplying the energy values of the glow-lamp by the ratio of densities, $\frac{\text { firefly light }}{\text { glow-lamp light }}$, from Fig. 9, at each wave-length. The resultant curves are given in Figs. Io and I I and tabulated in 'Tables $\mathrm{I}$ and 2.

In Fig. Io the spectral energy curve of Photuris pennsylvanica and Photinus pyralis are plotted to the same scale in the blue-green. An integration

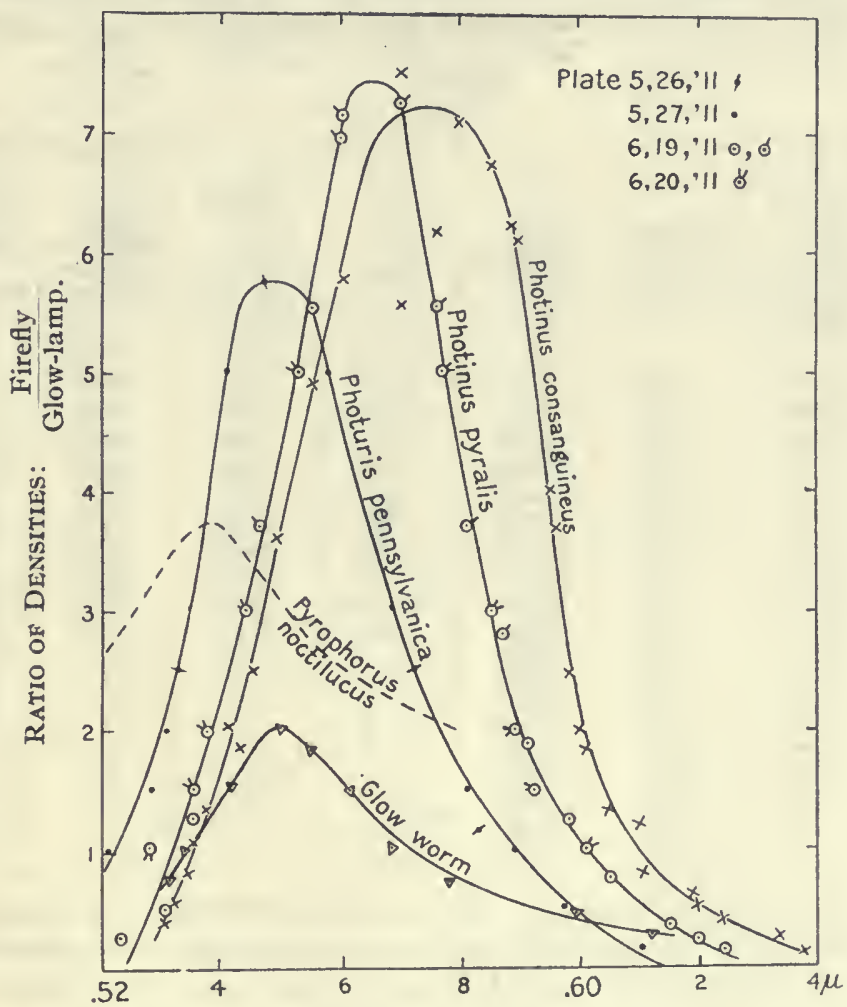

Fig. 9. - Ratio of densities of photographic plates (firefly light $\div$ glow-lamp light) obtained from the preceding illustrations.

of these two curves shows that for the same emissivity in the blue the energy curve of the Photinus pyralis is 2.83 times that of the pennsylvanica. 'To the eye it is apparent that the illuminating power of the Photinus is far greater than that of the Photuris. Whether the Photuris pennsylvanica curve is asymmetrical, as indicated in Fig. 10 , or symmetrical is difficult to decide because of the far greater sensitivity of the plate for the region of $0.59 \mu$, and the fewness of the negatives. The same irregularity occurs in the Photinus pyralis, but is somewhat obliterated by the nearness of the maximum of emission. 
In Fig. I I no special significance is to be attached to the tilted appearance of the energy curve of the Photinus consanguineus. A slight increase in the ordinates of the spectral energy curve of the glow-lamp at $0.60 \mu$ to $0.65 \mu$ would obliterate this effect. Then, too, the negatives are too small, and any slight shift from the point of reference in making the photometric measurements would change the symmetry of the curve. 'The first published curve* of Photinus pyralis was more asymmetrical than the present one, owing to the fact that the spectral energy curve of the glow-lamp, as then used, was steeper in the red than the one used in the present curves. 'The energy curve of the firefly then published does not superpose nicely upon the present one, being too flat at the top. From the present work it appears that this is due to the use of too greatly overexposed and underexposed photographs in

TABLE I.

\begin{tabular}{|c|c|c|c|c|c|c|c|}
\hline \multicolumn{4}{|c|}{ Photuris pennsylvanica. } & \multicolumn{4}{|c|}{ Glow-worm (larva of Photuris pentsylvaniea). } \\
\hline $\begin{array}{l}\text { Wave- } \\
\text { length. }\end{array}$ & $\begin{array}{c}\begin{array}{c}\text { Ratio of } \\
\text { densities: }\end{array} \\
\text { Firefly } \\
\begin{array}{c}\text { Glow-lamp } \\
\text { (Fig. 9). }\end{array}\end{array}$ & $\begin{array}{l}\text { Finergy } \\
\text { distribution } \\
\text { of carbon } \\
\text { glow-lamp. }\end{array}$ & $\begin{array}{l}\text { Tinergy } \\
\text { distribution } \\
\text { of firefly. }\end{array}$ & $\begin{array}{l}\text { Wave- } \\
\text { length. }\end{array}$ & $\begin{array}{c}\begin{array}{c}\text { Ratio of } \\
\text { densities: }\end{array} \\
\text { Glow-worm } \\
\begin{array}{c}\text { Glow-lamp } \\
\text { (Fig-9). }\end{array}\end{array}$ & $\begin{array}{c}\text { Iinergy } \\
\text { distribution } \\
\text { of carbon } \\
\text { glow lamp. }\end{array}$ & $\begin{array}{c}\text { linergy } \\
\text { distribution } \\
\text { of } \\
\text { glow-worm. }\end{array}$ \\
\hline $\begin{array}{c}0.520 \mu \\
.528 \\
.5305 \\
.5325 \\
.5345 \\
.541 \\
.547 \\
.557 \\
.568 \\
.5715 \\
.576 \\
.581 \\
.583 \\
.589 \\
.596 \\
.600 \\
.610\end{array}$ & $\begin{array}{l}1.00 \\
1.50 \\
2.00 \\
2.50 \\
3.00 \\
5.00 \\
5.75 \\
5.00 \\
3.00 \\
2.50 \\
2.00 \\
1.50 \\
1.33 \\
1.00 \\
.50 \\
.50 \\
.25\end{array}$ & $\begin{array}{l}3.30 \\
3.70 \\
3.82 \\
3.98 \\
4.02 \\
4.39 \\
4.72 \\
5.33 \\
6.10 \\
6.36 \\
6.74 \\
7.15 \\
7.32 \\
7.87 \\
8.50 \\
8.90 \\
9.90\end{array}$ & $\begin{array}{r}3.30 \\
5.55 \\
7.64 \\
9.95 \\
12.06 \\
21.95 \\
27.14 \\
26.65 \\
18.30 \\
15.90 \\
13.48 \\
10.73 \\
9.74 \\
7.87 \\
4.25 \\
4.45 \\
2.47\end{array}$ & $\begin{array}{c}0.531 \mu \\
.534 \\
.542 \\
.550 \\
.555 \\
.561 \\
.568 \\
.578 \\
.598 \\
.612\end{array}$ & $\begin{array}{l}1.50 \\
2.00 \\
3.00 \\
4.00 \\
3.70 \\
3.00 \\
2.00 \\
1.50 \\
1.00 \\
.50\end{array}$ & $\begin{array}{r}3.88 \\
3.98 \\
4.47 \\
4.92 \\
5.20 \\
5.61 \\
6.13 \\
6.92 \\
8.74 \\
10.14\end{array}$ & $\begin{array}{r}5.82 \\
17.96 \\
13.41 \\
19.68 \\
19.24 \\
16.83 \\
12.26 \\
0.38 \\
8.74 \\
5.07\end{array}$ \\
\hline
\end{tabular}

making up the composite curve. This made no difference in locating the maximum, which is practically the same as in the present determination, but the energy curve is distorted and flattened at the top. The irregularities in the old curve are similar to those obtained in the present work.

The "density" curve of Photinus consanguineus (the lower curve, Fig. 8) is irregular at $0.56 \mu$ and $0.58 \mu$, being the highest at the latter point. Another curve showed this same irregularity, but its highest point was at $0.56 \mu$. It is therefore doubtful whether there are two emission maxima in the consanguineus, although indicated by dotted lines in Fig. I I. In Fig. 8 the density curves of the carbon lamp found with the large spectrograph were used, while the photographic curves of the insects were obtained with the small spectrograph. 'This might make some difference in eliminating the small irregularities of the plate, but it can not have a marked effect upon the position of the maximum. 
In view of the fact that the color of the light of Photimus consanguineus and Photinus scintillans appears to be more variable than that of other fireflies, it would be of interest to determine whether they emit light composed of two bands, of which the one is yellow and the other is orange-red. A large dispersion would be required; and plates sensitized so as to be more uniform in their action in the red and yellow would be useful.

TABLE 2.

\begin{tabular}{|c|c|c|c|c|c|c|c|}
\hline \multicolumn{4}{|c|}{ Photinus pyralis. } & \multicolumn{4}{|c|}{ Photinus consanguinets. } \\
\hline $\begin{array}{l}\text { Wave- } \\
\text { length. }\end{array}$ & $\begin{array}{c}\begin{array}{c}\text { Ratio of } \\
\text { densities: }\end{array} \\
\text { Firefly } \\
\begin{array}{c}\text { Glow-lamp } \\
\text { (Fig. 9). }\end{array}\end{array}$ & $\begin{array}{l}\text { Iinergy } \\
\text { distribution } \\
\text { of carbon } \\
\text { glow-lamp. }\end{array}$ & $\begin{array}{c}\text { Iinergy } \\
\text { distribution } \\
\text { of firefly. }\end{array}$ & $\begin{array}{l}\text { Wave- } \\
\text { length. }\end{array}$ & $\begin{array}{c}\begin{array}{c}\text { Ratio of } \\
\text { densities: } \\
\text { Firefly }\end{array} \\
\begin{array}{c}\text { Glow-lamp } \\
\text { (1'ig. 9). }\end{array}\end{array}$ & $\begin{array}{l}\text { Energy } \\
\text { distribution } \\
\text { of carbon } \\
\text { glow-lamp. }\end{array}$ & $\begin{array}{c}\text { Einergy } \\
\text { distribution } \\
\text { of firefly. }\end{array}$ \\
\hline $\begin{array}{l}.0523 \mu \\
.527 \\
.530 \\
.534 \\
.535 \\
.537 \\
.544 \\
.546 \\
.553 \\
.555 \\
.560 \\
.570 \\
.576 \\
.577 \\
.581 \\
.585 \\
.587 \\
.589 \\
.590 \\
.592 \\
.598 \\
.601 \\
.60 \\
.615 \\
.620 \\
.623\end{array}$ & $\begin{array}{l}0.25 \\
1.00 \\
.50 \\
1.50 \\
1.50 \\
2.00 \\
3.00 \\
3.70 \\
5.00 \\
5.55 \\
7.00 \\
7.20 \\
5.55 \\
5.00 \\
3.70 \\
3.00 \\
2.78 \\
2.00 \\
1.85 \\
1.50 \\
1.25 \\
1.00 \\
.75 \\
.38 \\
.25 \\
.13\end{array}$ & $\begin{array}{r}3.45 \\
3.65 \\
3.78 \\
3.98 \\
4.05 \\
4.18 \\
4.57 \\
4.68 \\
5.07 \\
5.20 \\
5.55 \\
6.24 \\
6.74 \\
6.82 \\
7.15 \\
7.52 \\
7.68 \\
7.87 \\
7.96 \\
8.12 \\
8.72 \\
9.03 \\
9.40 \\
10.45 \\
11.05 \\
11.35\end{array}$ & $\begin{array}{r}0.86 \\
3.65 \\
1.89 \\
5.97 \\
6.08 \\
8.36 \\
13.71 \\
17.32 \\
25.35 \\
28.86 \\
38.85 \\
44.92 \\
37.41 \\
34.10 \\
26.45 \\
22.56 \\
21.35 \\
15.74 \\
14.73 \\
12.18 \\
10.90 \\
9.03 \\
7.05 \\
3.97 \\
2.76 \\
1.48\end{array}$ & $\begin{array}{c}0.522 \mu \\
.525 \\
.530 \\
.531 \\
.534 \\
.535 \\
.537 \\
.541 \\
.543 \\
.545 \\
.548 \\
.549 \\
.555 \\
.560 \\
.570 \\
.570 \\
.576 \\
.580 \\
.585 \\
.589 \\
.590 \\
.595 \\
.596 \\
.598 \\
.600 \\
.601 \\
.60 \\
.610 \\
.611 \\
.619 \\
.620 \\
.624 \\
.628 \\
.634 \\
.638 \\
.648\end{array}$ & $\begin{array}{r}0.2 \\
.5 \\
1.5 \\
2.0 \\
3.0 \\
4.3 \\
5.0 \\
7.5 \\
6.9 \\
9.3 \\
15.0 \\
13.5 \\
18.3 \\
21.6 \\
28.0 \\
20.7 \\
23.0 \\
26.5 \\
25.1 \\
23.2 \\
23.0 \\
15.0 \\
13.8 \\
9.2 \\
7.5 \\
6.9 \\
5.0 \\
4.5 \\
3.0 \\
2.3 \\
2.0 \\
1.5 \\
1.0 \\
1.0 \\
.5 \\
.2\end{array}$ & $\begin{array}{l}3.40 \\
3.53 \\
3.78 \\
3.83 \\
3.98 \\
4.05 \\
4.18 \\
4.39 \\
4.53 \\
4.64 \\
4.80 \\
4.87 \\
5.22 \\
5.54 \\
6.30 \\
6.30 \\
6.74 \\
7.09 \\
7.53 \\
7.89 \\
7.97 \\
8.44 \\
8.53 \\
8.72 \\
8.90 \\
9.03 \\
9.80 \\
9.91 \\
10.02 \\
10.91 \\
11.05 \\
11.50 \\
12.02 \\
12.80 \\
13.30 \\
14.61\end{array}$ & $\begin{array}{r}0.68 \\
1.77 \\
5.67 \\
7.76 \\
11.94 \\
17.42 \\
20.90 \\
32.93 \\
31.26 \\
43.15 \\
72.00 \\
65.75 \\
95.93 \\
119.66 \\
176.40 \\
130.41 \\
155.02 \\
187.89 \\
189.00 \\
183.05 \\
183.31 \\
126.60 \\
117.71 \\
80.20 \\
66.78 \\
62.31 \\
49.00 \\
44.60 \\
30.06 \\
25.09 \\
22.10 \\
17.25 \\
12.02 \\
12.80 \\
6.65 \\
2.92\end{array}$ \\
\hline
\end{tabular}

Having but one density curve (Fig. 8, $\bullet,-\infty,-\infty)$ of Photinus scintillans, and this one being too much overexposed to work out the central part of the curve, no exact value of the maximum emission of this insect has been obtained. The density curve is symmetrical with a similar one of the Photinus consanguineus, and, in view of the fact that to the eye there is no marked difference in the color of the light (the flash) emitted by these two species, the maximum emission of scintillans is taken to be the same as that 
of consanguineus. It is possible that when subjected to a thorough analysis the maximum emission of the scintillans will be found still farther toward the red, say $0.58 \mu$. From the photometric curve, Fig. 9, obtained by Langley and Very,* the maximum emission (not applying the energy curve of the comparison source) of the Cuban firefly, Pyrophorus noctilucus, occurs at $0.538 \mu$. Two determinations by Dubois, $\nmid$ using a grating, gave $\lambda=0.53 \mu$ as the point of maximum emission.

In connection with the much-discussed question of the physiological effect on the eye, it is of interest to note the description, by Dubois, of the variation in the color of the light emitted by Pyrophorus. He says that when the light diminishes in intensity the red and orange rays disappear and at last

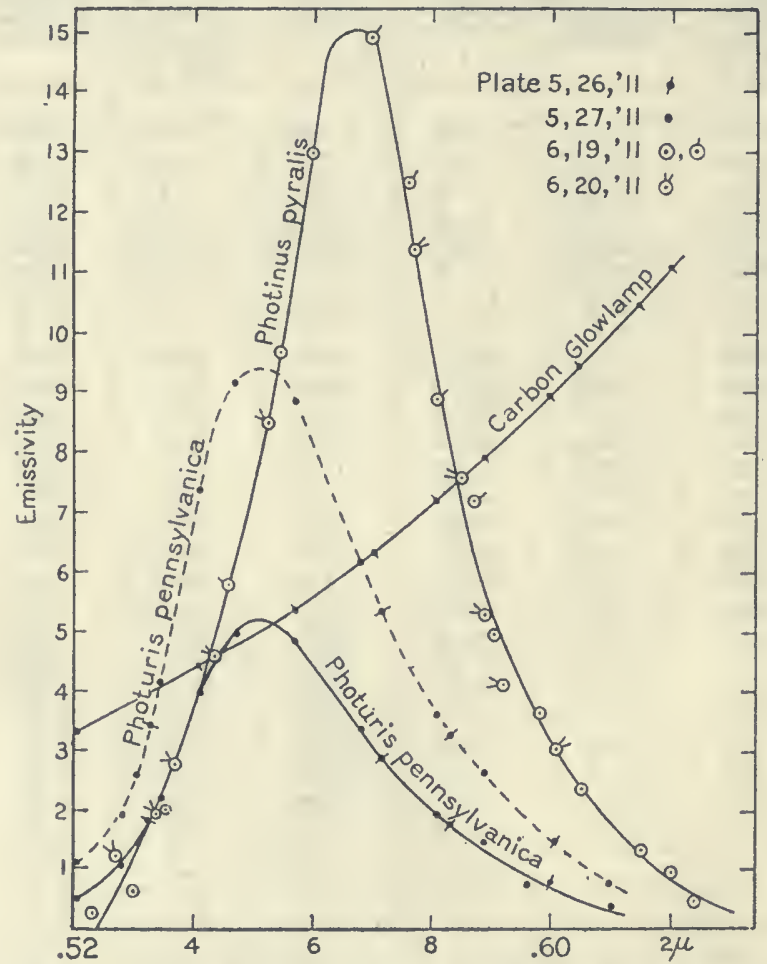

FIG. I0.-Spectral energy curves of fireflies and glow-lamp.

only the green rays persist; and that when the animal begins to emit light the green rays first appear, then the color extends farther and farther into the red, when the light attains its maximum intensity.

In concluding this section it may be added that for the first time we liave substantial evidence that the color of the light of various fireflies is different, the maximum emission varying from $0.55 \mu$ in the bluish light of the Photuris pennsylvanica to $0.58 \mu$ in theorange-red light of the Photinus consanguineus. Evidently, in these extreme cases the eye made no serious mistake in assign-

${ }^{*}$ Langley and Very, Amer. Jour. Sci. (3), 40, I890. Smithsonian Mis. Collections No. 1258,1901 .

†Dubois, Leçons de Physiologie générale et comparée, Paris, 1898. 
ing the color values which correspond with these maxima. A mere glance at the photographic curves of the light of the same insects, obtained with

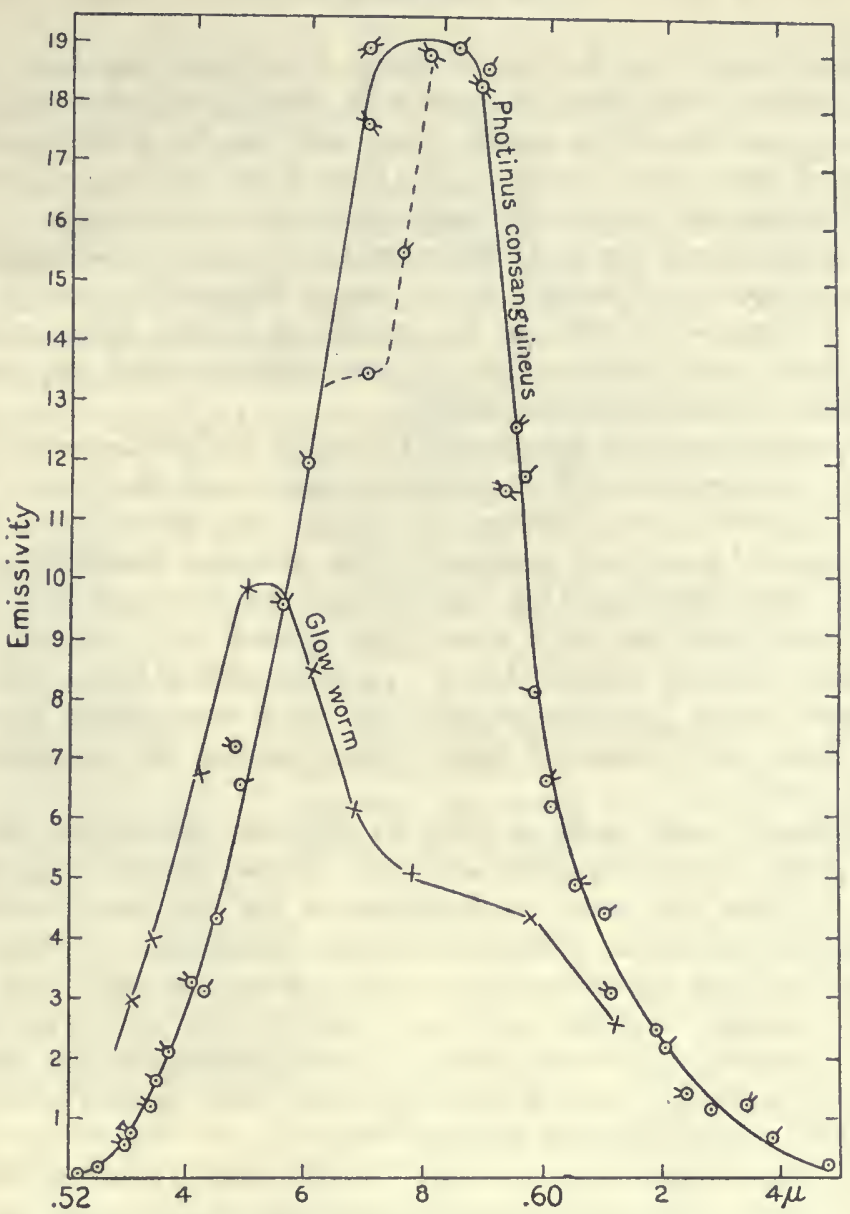

Fig. Ir.-Spectral energy curves of firefly and glow-worm.

different apparatus, as shown in Figs. 7 and 8, should suffice to demonstrate this point. 'The emission maxima of the various insects studied are shown in Table 3 .

TABLE 3 .

\begin{tabular}{|c|c|}
\hline Animal. & Maximum of emission. \\
\hline 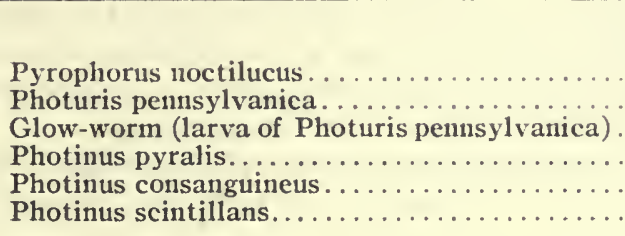 & $\begin{array}{l}\mu \\
0.538 \text { to } 0.540 \\
.552 \\
.552 \\
.567 \\
.578 \\
.578 \text { to } 0.580\end{array}$ \\
\hline
\end{tabular}




\section{LUMINOUS EFFICIENCY AND CANDLE-POWER MEASUREMENTS.}

In the experiments on the Cuban firefly, Pyrophorus noctilucus, Langley* and his assistants found that to the eye the insect gave one-eighth as much light as an equal area of the candle flame, and that the actual candle-power of the insect was I/ 1600 candle. The light from this insect appears to be emitted continuously, but to fluctuate somewhat in intensity.

Accurate measurements on a fluctuating source, such as the flashes emitted by the local species of fireflies, is, of course, impossible; but it is lighlily desirable to lave some idea of the magnitude of the light emission. A simple "grease spot" photometer was therefore provided, the comparison source being a standard sperm candle.

In the measurements on the glow of the firefly, the photometer screen was placed at 5 meters from the comparison source and the insect, with the luminous segments turned toward the screen, was moved back and forth until the neutral point was reached. This distance varied from r.o, I.5, to $2.2 \mathrm{~cm}$., depending upon the intensity of the glow and the size of the insect. Some specimens for a short time glowed very strongly, $1 / 50,000$ candle, then suddenly decreased to $1 / 150,000$ candle or less. The weakest measurements were $\mathrm{I} / 250,000$ candle; but these were strong as compared with the faint glow observed while photographing the spectrum of the Photinus scintillans.

Measurements were made of 8 to ro different specimens, the average intensity of the glow being of the order of $1 / 50,000$ candle. Because of the inability to cause the insect to flash rapidly for any length of time, the measurements were more difficult, and hence uncertain. In this case the insect was held over a glass plate at a fixed distance (about $7.5 \mathrm{~cm}$. from the photometer screen), and the latter was moved back and forth before the comparison source. The main difficulty encountered was the variation in intensity of the flash. A fresh specimen sometimes emitted several strong flashes which would suddenly become weak.

As in the measurements on the glow, the specimens examined were of two kinds, viz, fireflies that had been in captivity for over a week and fireflies that had just been caught in the fields. Several other simple tests were tried, but no satisfactory measurements were made of the flash, due principally to the great fluctuations in intensity. The measurements on the candle-power of the flash indicated a variation from I/50 candle to $\mathrm{I} / 400$ candle, the predominating values being $\mathrm{I} / 400$ candle. In all, about a dozen measurements of the intenstity of the flash were made on three healthy specimens of Photimus pyralis. It would have been interesting to make similar measurements of the Photuris, but it was too late in the season. As mentioned elsewhere, male specimens of the latter are frequently obtained which emit a "twinkling" flash 3 times per second, and will sometimes continue to do so for I to $1 \frac{1}{2}$ hours without serious interruption.

In the previous investigation the radiant efficiency† of the Photinus pyralis was found by multiplying the spectral energy curve by factors representing

*Annals Astrophys. Obs., 2, p. 5, 1902.

$\dagger$ Ives and Coblentz, Bull. Bur. Standards, 6, p. 330, 1909. 
the visibility of the radiation. In the meantime these factors liave undergone revision, ${ }^{*}$ and in the present work the spectral energy curves given in Figs. 9 and ro were multiplied by these new factors, the numerical values for high intensities being used. 'The resulting spectral energy curve, Fig. 12 , is similar to the one previously published. $\dagger$ 'The ratio of the area of this curve (the ratio of shaded area to the total area of the spectral energy curve), which represents the most advantageous possible distribution of light to the eye, to the area of the spectral energy curve of all the light emitted (i. e., energy radiated $\times$ visual sensibility $\div$ the total radiated energy) is the reduced luminous efficiency. An integration of the curves thus obtained indicated that this reduced luminous efficiency of the Photinus consanguineus is about 79 to 80 per cent, that of the Photinus pyralis is about 87 per cent, and that of the Photuris pennsylvanica is about 92 per cent. The latter emits the bluer light, corresponding more nearly with that part of the

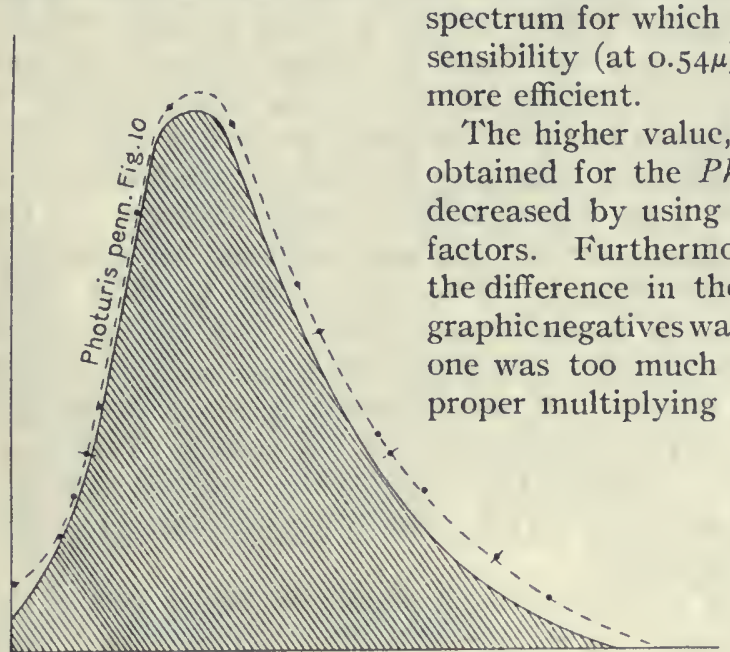

Fig. 12.-Luminous efficiency of firefly (shaded area to total area). This curve is taken from Fig. Io. ithe hight. spectrum for which the eye has its maximum sensibility (at $0.54 \mu$ ) and hence should be the the Pholinus pyralis, would be Pholinus pyralis, would be the difference in the densities of the photographic negatives was too great, and the denser one was too much over-exposed, to obtain a proper multiplying factor which would give the proper intensities of the central (lighest) part of the curve representing the ratios of firefly light to glow-lamp light. This tends to give too high values for the radiant efficiency.

To the writer this method of estimating the luminous (radiant) efficiency seems misleading, for the reason that individual eyes vary too much $\ddagger$ to attempt to define this quantity in terms of the "average eye." 'Then, too, in the ultimate analysis, the question of real interest is the total cost of production and the total quantity of the commodity produced. The aforesaid value of the radiant efficiency of the firefly is obtained on the assumption that there is no infra-red radiation emitted. It will be shown presently that thus far it has been impossible to detect infra-red radiation, and hence the high numerical values obtained for the radiant or luminous efficiency (ratio of "light" to total radiation) seem plausible; but it is misleading if we overlook the question of the energy input, about whicl we have no information.

${ }^{*}$ P. G. Nutting, Visual sensibility of the eye, Bull. Bur. Standards, 7, p. 235, 1911. Circular Bur. Standards 28, p. 8.

†Bull. Bur. Standards, vol. 6, No. 3, p. 331 .

†Ives, Trans. Illum. Eng. Soc., 6, p. 258, I 9 I I. 
From his four summers' experience with these insects, during which time hundreds of them were caught, and a great number of the stronger ones were handled on the spectrometer slit, the writer has come to the conclusion that, in emitting the light, considerable energy is expended in some unaccountable manner. After a period of flashing (the frequency of which is stimulated by the mere effort of the insect's struggling to escape) the light emission suddenly decreases in intensity. After a short rest the flashing may again be obtained; but after repeated trials the flash ceases and the glow may begin. If the insect now be agitated, the characteristic glow appears, and after a short time life becomes extinct, apparently from exhaustion.

The Photuris is very strong and furnishes good examples. After being held on the spectrometer slit, and after having flashed until tired and then placed away, it was found that they never recovered, when examined the next day. On the other hand, samples caught the same evening, but not used until the next day, were then very active and flashed as frequently and sometimes as intensively as those caught and used on the same evening. A specimen that had flashed from two to three times per second for half an hour without tiring was given a rest of an hour, after which it flashed with the same rapidity for another hour, then suddenly ceased flashing. In the meantime it had remained quiet over the spectrometer slit and hence escaped the continual handling usually necessary to keep a specimen in place. 'This specimen was then placed alone in comfortable quarters, but it never recovered, life being extinct the next day, although quite active (except in light emission) when given its freedom. It was apparent that the insect had not ceased flashing because of any injury received, but because of the exertions in emitting the light. Whether this exertion was entirely muscular effort and whether the light ceased as the result of the exhaustion of the fuel supply are pertinent questions.

In concluding this phase of the subject it should be noted that if the radiant efficiency had been rated as was done by other experimenters (viz, all light, no invisible rays, and not applying the correction for visual sensibility) the numerical value would be 100 per cent, as found by Langley.

'To the writer this manner of rating the luminous efficiency is far from satisfactory. For example, it has just been noticed that bluish-green light from the Photuris has the highest luminous efficiency of the three species examined and one might conclude that it would be the most economical light. From the standpoint of actual illumination this does not necessarily follow. For example, in Fig. 1o (where the spectral energy curves of the Photuris and the Photinus pyralis are plotted to the same scale in the green, $0.54 \mu$ ), it may be noticed that when the intensity of the light is the same in the blue-green the total amount of light obtained from the Photinus pyralis is 2.83 times that of the Photuris. It would be interesting to determine the specific emissivity of the light organs of these insects, in spite of its great variability. 'The aforesaid curves simply show that if we obtain the same emissivity in the blue (by varying the relative distance of the two sources or the size of the luminous organs or by varying the specific emissivity of the luminous organs) the Photinus pyralis sends out at least 2.8 times the "light" (visual sensation) emitted by the Photuris, even though it is not 
brought about with the same efficiency as regards the effect upon the retina. This appears very interesting viewed from the standpoint of the needs of the human eye. But how do we know that the insect's eye requires light fulfilling our specifications; and if it does, why not say that the color of the light varies for æsthetic reasons, rather than the more plausible one that it serves as a mark of distinction between the various species?

\section{RADIATION AND TEMPERATURE MEASUREMENTS.}

The more recent attempts of Langley* and his assistants to measure the radiation from the $\mathrm{Cuban}$ firefly show that if there are radiations lying beyond the visible spectrum their heating value is immeasurable. The earlier measurements of Duboist seemed to indicate the presence of infra-red radiation, but in view of the greater radiometric sensitivity now attainable and the greater precautions taken to exclude extraneous radiations, the older measurements must be assigned but little weight. The measurements of Dubois indicate a very considerable amount of radiation (the galvanometer deflection being $1.8^{\circ}$ ) from the luminous organs of the Cuban firefly. The dark parts of the body of the insect emitted radiation causing a deflection of $0.95^{\circ}$. It is difficult to understand how, with the facilities now available, these radiations, if present, can escape detection.

The present measurements were first undertaken on samples of the Cuban firefly (Pyrophorus noctilucus). Out of the two dozen in the original shipment, only one survived in transit, and this one was too weak for radiation measurements. 'Thinking that the lack of intensity might be compensated by using a larger radiating area, measurements were undertaken on the luminous organs of the local firefly, when stimulated so as to emit a rich glow. As mentioned elsewhere, a slight pressure on the luminous segments will cause a strong glow. A vacuum thermopile, exhausted by means of liquid air and charcoal (after preliminary evacuation with an oil pump) was used as a radiometer. The sensitive parts consisted of a fine platinum wire $0.1 \mathrm{~mm}$. in thickness, and a strip of bismuth rolled to $0.02 \mathrm{~mm}$. thickness, $6 \mathrm{~mm}$.long, and of the shapeindicated in Fig. $13, B$. The platinum wire was used because of the ease with which it could be "tinned" and soldered to the bismuth with Wood's alloy. The latter ordinarily makes a poor highresistance connection, but this is easily remedied by coating the wire (platinum or iron) with solder. The wide circular area, constituting the receiver, was blackened with a mixture of lamp-black and platinum-black. The outside of the glass tube was covered with tin-foil, except openings on opposite sides of sufficient size to admit radiation on the sensitive junction and for the purpose of adjustment. This thermopile was entirely free from the lag usually found in such instruments. The heating attained its maximum in less than 2 seconds, which was the time required for the galvanometer to reach the maximum deflection.

It will be noticed that in certain work, for example where the insect was near the instrument, radiation fell on both junctions, and hence not operating at its maximum efficiency. On actual trial it was found that it made

*Annals Astrophys. Obs., 2, p. 5, 1902.

†Dubois, Bull. Soc. Zool. France, parts 1, 2, and 3, 1886. 
no appreciable difference to expose the two junctions or only the dark junction to radiation. 'This is due in part to the smallness of the bright junction. The radiating of such a thermopile by the candle test has but little meaning because of the absorption by the glass walls, which absorb perhaps 40 to 50 per cent of the incident radiation. 'The test was applied, however, giving a deflection of $2.5 \mathrm{~cm}$. for a sperm candle at 2 meters and galvanometer sensitivity of $i=3 \times 10^{-10} \mathrm{amp}$., or $10 \mathrm{~cm}$. for a candle at $\mathrm{I}$ meter.

In actual work on fireflies the galvanometer sensitivity was increased to $i=1.5 \times 10^{-10} \mathrm{amp}$. to $7 \times 10^{-11} \mathrm{amp}$. or 5 times as sensitive as for the candle test. In his measurements Langley found that:

A portion of the flame of a standard sperm candle, equal in area to the bright part of the insect, gave, under the same circumstances, a bolometric effect of such magnitude that had the heat of the insect between $\mathrm{I} / 80,000$ been as great as this from the candle, it would certainly have been recognized.

The sensitivity of the present apparatus, under conditions similar to those just quoted, was such that radiation $\mathrm{I} / 60,000$ as great as that of the candle would have caused a deflection of $1 \mathrm{~mm}$. The thermopile in vacuum

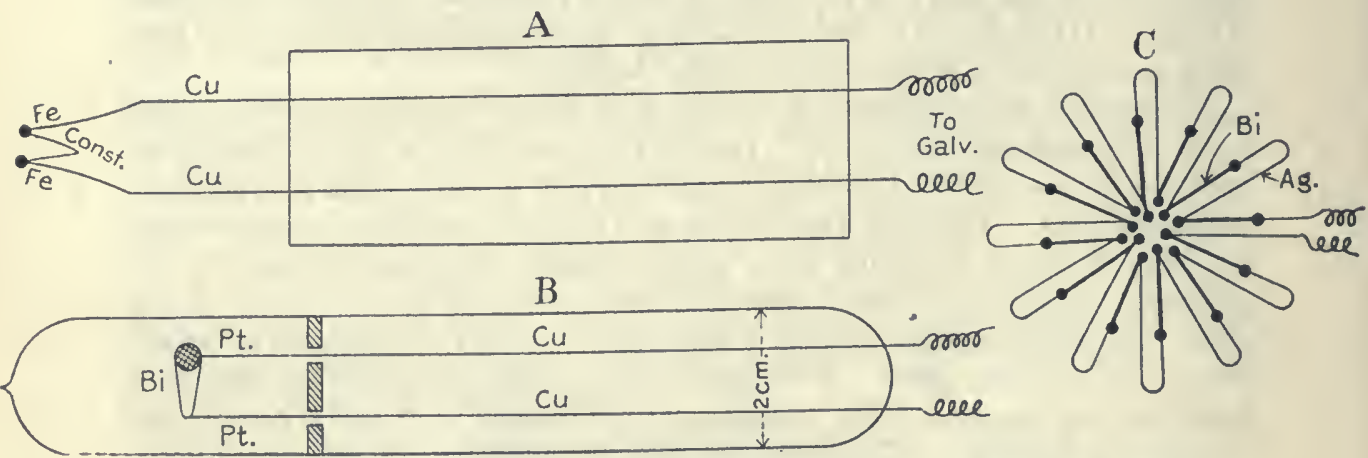

FIG. 13.- Thermopiles for measuring the temperature and radiation of fireflies.

is far more steady than a bolometer in air and covered with a glass window, so that while the present sensitivity appears to have been less than that used by Langley and his assistants, the efficiency or reliability was no doubt considerably greater. 'That the sensitivity of the instrument was very high is indicated by the fact that when a firefly was placed on the glass walls over the sensitive junction, or within 5 to so $\mathrm{mm}$. of the same, the galvanometer indicated a cooling of this junction which attained its maximum in about I minute.

It will be shown presently that the temperature of the firefly is somewhat less than the surrounding air; hence in the heat interchange the pile would radiate to the insect. However, the radiation from the pile could not pass through the glass, and the explanation offered is that the glass was cooled (principally by conduction) by the insect and in turn the dark junction radiated to the glass; whence the slowness of the operation. This observation of a cooling effect when the insect was near the thermopile came as a surprise, and for a while it appeared that there might be an endothermic action taking place in the photogenic cells instcad of the long-sought-for 
heat radiation. However, it is not considered a true endothermic phenomenon caused by the absorption of heat by the photogenic organs, but is rather a slow conduction of heat from the walls of the radiometer to the insect, which is at a lower temperature. If the phenomenon is one of a true transfer of radiant energy, then the galvanometer should have reached its maximum deflection in 4 seconds instead of 60 to 80 seconds, and it should have remained at a maximum instead of slowly drifting back after the expiration of $\mathrm{r} .5$ to 2 minutes. 'The crucial test would be to use a rock-salt window which would permit the long-wave radiation from the thermo-junction to pass directly to the insect, instead of impinging on the glass walls of the radiometer. This cooling effect led to the thermo-couple explorations to be described presently.

The radiometric tests of the flash and the glow of both Photuris pennsylvanica and Pholinus pyralis extend over a period of 3 weeks, during wlich time four distinct series of measurements were made; each series took from I to 3 hours, during which time various experiments were tried, using red absorption glass, etc. In the earlier measurements on the Photuris the insect was attached to a thin wooden rod about ${ }_{15} \mathrm{~cm}$. long, held horizontally and suspended over the thermo-junction. The tests were made in a darkened room and shields were provided so that no stray light could get into the thermopile case. The flashes were as frequent as 3 times per second, but in neither the flash nor the steady glow could any radiation be detected with certainty other than the cooling effect (conduction of heat) which will now be discussed.

If it were not for the novelty of the phenomenon and the averseness with which one views data of this type, after having been taught to search for a heating effect rather than the opposite, it would be possible to urge that the emission of light is accompanied by an absorption of heat. For example, a strong, active Photuris, flashing 80 to 90 times per minute, caused a cooling effect of 5 to $6 \mathrm{~cm}$. deflection (galvanometer period 4 seconds, therefore very steady and no "drift); and later on, when the flashes became less frequent, in two distinct series of measurements the maximum (cooling) deflection was in each case only $3.5 \mathrm{~cm}$. Another specimen gave a (cooling) deflection of $1.5 \mathrm{~cm}$. and then began "flashing brighter" (as the records have it), when the deflection increased to $3.1 \mathrm{~cm}$. Still another specimen of Photuris, "flashing 3 times per second," gave a maximum (cooling) deflection of 6 to 7 $\mathrm{cm}$., and finally only $2.2 \mathrm{~cm}$. deflection. The records show several similar cases. Whether these measurements have any significance it is difficult to say. The closer to the radiometer the greater was the cooling, but it is not known whether the insect was accurately at the same distance from the walls of the radiometer when flashing and when it became less active.

If the insect generates only the radiations which are visible to the eye, the heating value of these rays will be small. It is evident that but little infrared radiation can be generated, for so much would be absorbed that unless it has some cooling device the temperature would rise to a high value and the insect would be speedily desiccated. It is therefore possible to have the radiation (heating) effects on the radiometer masked by the thermal conduction effects (cooling) if the temperature of the insect is less than that of the thermopile. 
This apparent increase in the cooling effect in the more active (flashing) state of the insect is a complex phenomenon requiring further investigation. As it stands, it could not be verified by the iron-constantan thermo-couple measurements on the temperature of the different parts of the body of the insect. 'The thermo-couple shows, Fig. $13, A$, that the temperature of the insect is lower than the air (this is in agreement with the radiometric observations), and that, used differentially, the temperature of the luminous segments is higher than the rest of the body; but it was not possible to show with certainty whether the temperature of the luminous segments varied (apparently decreased by the radiometric test) during the act of flashing.

After trying out these heat-conduction effects with the insect close to the vacuum thermo-element, the radiometric apparatus was arranged so that a mirror, $15 \mathrm{~cm}$. in focal length and $10 \mathrm{~cm}$. diameter, projected an image of an opening $(2.5 \mathrm{~mm}$. diameter $)$ in a heavy black cardboard upon the active thermo-junction. 'The whole was covered so that no radiation, except that which passed through the opening in the cardboard, could fall upon the thermo-element. The firefly was then held with the luminous segments over the opening in the cardboard. Both glowing and flashing specimens were examined, but in only one instance was any deflection (a kick) observed that might be interpreted as possibly being due to the light (flash) from the firefly. It was therefore concluded that, since the glass wall of the bismuthplatinum thermo-element absorbed the long waves, no radiations less than $3 \mu$ were observable. The radiations which are greater than $3 \mu$ would fall in the category of "animal heat," which will now be discussed.

Langley avoided the effect of "animal heat" by interposing a glass screen, which prevented an interchange between the insect and the radiometer of radiations greater than 3 to $4 \mu$. It has just been noticed that under certain conditions, when the insect was near (or touching) the glass walls of the thermopile, the deflection of the galvanometer indicated that the sensitive junction was losing heat by radiation; and, from the slowness of the action, that this was due to the local cooling of the glass wall surrounding it. Evidently conditions might be brought about whereby a heating effect, caused by a true radiation from the insect, might be counterbalanced by a cooling effect (conduction) due to a difference in temperature between the insect and the radiometer, the latter being at the higher temperature. Furthermore, if the light production is a biochemical process, as some believe it to be, it is important to know whether this low temperature is due to the fact that we are dealing with a "cold-blooded" animal, or due to an endothermic reaction. 'Thermometric measurements were accordingly undertaken to determine the nature of the heat distribution in the body of the firefly. The first tests were made radiometrically with the vacuum thermo-element just discussed. It was found that the glowing luminous segments, when separated from the rest of the insect and placed upon the vacuum thermopile, exerted a certain cooling effect which decreased when life was extinct. An insect on its back caused a cooling, but it was impossible to determine by the vacuum thermo-element whether there was a difference in the temperature of the dark and luminous segments.

These experiments were continued by exploring the temperature distribution in the segments of the insect. For this purpose, thermo-couples of 
iron-constantan were employed. Two types of couples were tried. The couple shown in Fig. $\mathrm{r}_{3}, A$, consisting of wires $0.005 \mathrm{~mm}$. in diameter (the constantan wire being about $3 \mathrm{~cm}$. long) attached to heavy copper wires mounted upon a wooden base, proved the more satisfactory. In this instrument the junctions were fine globules of solder hammered flat and blackcned. In the second type the iron wire ( $0.2 \mathrm{~mm}$. in diameter) was filed to a point to pierce the outer integument. The great thickness of the iron introduced heat conductivity, which sometimes introduced irregularities, either heating or cooling, when only one of these effects was supposed to be present. It was difficult to operate and hence was discarded for the couple made of fine wires just mentioned. The latter was laid on several folds of cheese-cloth, which reduced the effect of air-currents. The experiments were carried on in a well-darkened room. The effects observed being so marked, it was necessary to reduce the sensitivity of the galvanometer (half period usually I second; $i=7 \times 10^{-10}$ ampere) and keep a resistance varying from 200 to 700 ohms in series with it.

The insect was attached to a thin wooden $\operatorname{rod}\left(\mathrm{r}_{5} \mathrm{~cm}\right.$. long, and held horizontally) in such a manner that it could be made to touch either one or both of the thermo-junctions. Covering either one or both of the junctions by means of a bit of cork or a dead insect, attached to the rod in the same manner, produced no effect. It is therefore evident that the thermal measurements made on live active insects are realities and not due to instrumental errors. Furthermore, the galvanometer deflections were decisive, not a few millimeters, but usually from I 5 to $20 \mathrm{~cm}$. and frequently "off the scale." The results are not based upon a series of measurements in which the mean of the positive deflections outweigh the mean of the negative deflections, or vice versa.

While the magnitude of the deflections varied enormously, owing to poor contact, one could continue for ro to 30 minutes at a time with rarely a false reading. For example, starting with the first or second abdominal (the luminous) segment, Fig. I, touching the upper thermo-junction, Fig. I $3, A$, the galvanometer would indicate a cooling of this junction which was usually "off the scale." - Rotating the insect about a vertical axis through $90^{\circ}$, with the luminous segment over the junction and with the third (adjacent) dark segment on the lower junction, the galvanometer would go off the scale in the opposite direction, indicating that the upper junction is now the hotter. In other words, while the insect is cooler than the air in the room, the differential measurements show that the luminous segments are hotter than the dark segments. Reversing the operation by starting with one of the luminous segments touching the lower junction (cooling), then with one of the dark segments on the upper junction, the galvanometer deflection indicated that the lower junction was now the hotter.

Sometimes only the heating effects would be tested, starting, say, with a luminous segment on the upper junction and a dark segment on the lower junction, then the reverse, and the test would be kept up in rapid succession for Io to I 5 minutes, when another insect was tried. In this series there should always have been a heating. Sometimes there would be a cooling effect and, on examination, it would be found that the dark segments were not touching the thermo-junction. While sucl a series was in progress, and 
everything going smoothly, variations would suddenly be introduced. For example, the two couples would be brought close together, so as to touch a single segment, luminous or dark, when no effect would be observed-the reader at the galvanometer not being aware of the change.

Turning the insect on its back and proceeding in the above-described manner, it was found that the region above the luminous segments was hotter than the region of the dark segments, just as was observed for the ventral side of the insect; but the difference in temperature betwcen the region of the luminous segments and the dark segments was less than when measured on the ventral side.

Placing one junction on a luminous segment and the other junction on the dorsal part of the same segment (dorsal-ventral temperature) the measurements were subject to greater fluctuations, hence not very conclusive. There was some evidence that the region directly over the luminous organs is hotter than the dorsal part of the same segment. This test was applied only to the Photinus pyralis, the Photuris being too active for any measurements of this kind. In one very concordant series of measurements on the Photinus, of the difference in temperature between the dark and the luminous segments, it was observed that on the dorsal side the temperature difference was only about half as great as on the ventral side, where the luminous organs are close to the surface. Comparing different species, it was found that the Photinus pyralis seemed hotter (the temperature difference between the bright and dark segments) than the Photuris pennsylvanica.

Dry specimens had no effect; but in dead specimens in which the luminous organs had begun to glow (putrefaction) there appeared to be a small heating. A freshly killed specimen seemed to come to room temperature (no cooling) very quickly; but the glowing luminous segments were always hotter than the dark segments. After a time this heating effect decreased, but on stimulating the luminous organs to a bright glow the usual "off the scale") heating effect became more nearly normal.

In the female Photinus pyralis the luminous organ is a small circular spot on the third abdominal segment from the end (see Fig. I). On placing one junction on the luminous spot and the other junction on the second segment from the end, the galvanometer showed that the luminous spot was much lotter than the other segments. In fact, in the first trial, the indication was so decided that the galvanometer reading was thrown entirely off the scale, requiring considerable time to bring it back into adjustment.

Both the male and female of Photinus pyralis have two small glowing luminous points, Fig. $I$, on the next to the last abdominal segment. The thermo-couple test on one of these glowing points, on the female just 1nentioned, indicated a higher temperature than the adjacent dark segment.

The complete thermo-couple test comprised four distinct series of measurements made on as many different days, those on the Photinus pyralis being made some 26 days later than the measurements on the Photuris. Of the Photuris, two males and three females, and of the Photinus pyralis, eight males and one female were subjected to thorough tests. Numerous other specimens were discarded before completing a test, because of accidents or inactivity.

These experiments are described in such detail because of their novelty, 
and more especially because of the question of the reality of the results. The tests were repeated when doubts arose at various times during an interval of more than 3 weeks, the instruments having been dismounted in the meantime, and they always led to the same result, viz, that the temperature of the insect is less than the air and that the region of the luminous segments is hotter than the dark segments.

In these experiments no attempt was made to obtain exact measurements of the difference in temperature of the luminous and the non-luminous segments. Indeed such data would be illusory. A rough estimate of the temperature may be obtained from a knowledge of the galvanometer sensitivity, the thermo-electric power of the junctions, and the resistance of the circuit. Using these constants, and assuming a deflection of $20 \mathrm{~cm}$., the equivalent difference in temperature is $0.6^{\circ}$. Frequently the indicated temperature was only $0.3^{\circ}$ to $0.5^{\circ}$, while the "off the scale" deflections indicated temperature differences as great as $0.8^{\circ}$. 'The bright luminous points, $L^{\prime}$, Fig. I, on the female pyralis indicated a temperature of $0.2^{\circ}$ above the surrounding dark regions. With the thermo-couples it was not possible to determine with certainty whether the deflections were increased (a heating) during the flash. The experiment showed that this temperature difference was present continuously in healthy specimens. This would seem to indicate that even if the temperature difference is due to some biochemical reaction, the light emission is under the control of the insect. The breathing spiracles being over all of the segments, it is difficult to understand how the influx of oxygen could produce a local effect in the luminous organs, unless there is some chemical action in these organs.

The galvanometer deflections were of the same magnitude for the cooling effect as they were for the lheating effect. This seemed to indicate that the temperature of the insect was not much below that of the room $\left(26^{\circ} \mathrm{C}\right.$.) at the time of the experiment. Hence, having been informed that the temperature of these insects is about $17^{\circ}$ to $18^{\circ}$, and that these measurements had been made by placing a number of insects in a vessel containing a thermometer, the writer undertook a similar experiment. Two similar glass specimen tubes, $15 \mathrm{~cm}$. long, $2 \mathrm{~cm}$. diameter, and two similar thermometers were provided. The thermometers passed through corks fitted into the tubes. These tubes were placed side by side in a vessel containing cotton batting. More than 100 Photinus pyralis were caught and shaken directly from the net into one of the glass tubes, which was then about half full of insects. After replacing the tube in the insulating material and waiting Io minutes, the writer was surprised to find that the temperature had risen $I^{\circ}$ above the empty tube instead of dropping to a lower temperature. 'Table 4 shows the course of events during the test. During the evening, as the activity of the insects decreased, the temperature difference decreased. Interchanging the places of the test tubes showed no variation in the readings, and the conclusion arrived at was that the temperature rise was due entirely to the presence of the insects. In view of the fact that the body temperature of these insects appeared to be almost as much below the room as the temperature of the luminous segments was above that of the insect, it is not unthinkable that in the thermally insulated vessel it was possible for the temperature to rise as observed. 
'The preceding pages give an exact account of the observations, an explanation of which is not attempted. However, in concluding this subject, it may not be out of place to add that an explanation based on the assumption that the dark segments are at a lower temperature than the luminous segments, due to their higher emissivity, does not appear satisfactory. As for the oxidation theory, the present data do not refute it. Whether this temperature difference has anything to do with the photogenic processes remains an undecided question. It seems to be present all the time in a healthy insect, but is not observable on a freshly killed non-glowing specimen. As stated elsewhere, several dead specimens were found which had begun to decompose, and the luminous organs emitted a faint glow. Thermo-couple measurements on these samples showed but a slight warming, if any, over the luminous segments.

TABLE 4.

\begin{tabular}{|c|c|c|c|c|c|}
\hline \multicolumn{2}{|c|}{$\begin{array}{l}\text { Time, } \\
\text { p. m. }\end{array}$} & $\begin{array}{l}\text { Temperature } \\
\text { of empty } \\
\text { test tube. }\end{array}$ & $\begin{array}{l}\text { Temperature } \\
\text { of test tube } \\
\text { containing } \\
\text { fireflies. }\end{array}$ & $\Delta_{t}$ & Remarks. \\
\hline & & 。 & ○ & ○ & \\
\hline & 20 & 30.6 & 30.6 & 0.0 & $\begin{array}{l}\text { Start; temperature read just before fill- } \\
\text { ing test tube. }\end{array}$ \\
\hline 8 & 30 & 30.6 & 31.6 & 1.0 & \\
\hline & 40 & 30.4 & 31.3 & 0.9 & Insects less active. \\
\hline 9 & $4^{0}$ & 30.2 & 30.3 & 0.1 & $\begin{array}{l}\text { After return from field, nearly all insects } \\
\text { inactive at bottom of test tube. }\end{array}$ \\
\hline 9 & 48 & 30.2 & 30.7 & 0.5 & $\begin{array}{l}\text { After shaking the test tube, eovering the } \\
\text { thermometer with lively insects, and } \\
\text { waiting } 8 \text { minutes. No effect due to } \\
\text { shaking. All but about a dozen } \\
\text { insects inactive, active ones at top; } \\
\text { put thermometer there. }\end{array}$ \\
\hline 10 & 02 & 30.5 & 30.8 & 0.3 & \\
\hline 10 & 20 & 30.5 & 30.8 & 0.3 & Interchanced nlaces of test tubes \\
\hline 10 & 25 & 30.3 & 30.6 & 0.3 & A gitated test tube: inserted therm. \\
\hline to & 30 & 30.3 & 30.7 & 0.4 & $\begin{array}{l}\text { Agitated living mass of insects. } \\
\text { in living }\end{array}$ \\
\hline 10 & 33 & 30.4 & 30.8 & 0.4 & \\
\hline 10 & 35 & 30.4 & 30.8 & 0.4 & \\
\hline
\end{tabular}

As a final summary of this perplexing series of experiments, it may be added that the temperature of the firefly is somewhat lower than the air, but it is not known whether this body temperature has a fixed value; that the luminous segments are hotter than the adjoining dark segments, this temperature difference being most marked on the ventral side of the insect; that it is uncertain whether this temperature difference is effected by the flash (whether the flash is accompanied by an endothermic or exothermic reaction); and that, if radiant energy (especially the infra-red) is emitted by these insects, it is immeasurably small. No suggestions are offered as to the cause of this difference in temperature between the luminous and the non-luminous segments. Apparently there are slight discrepancies in the two sets of measurements of the effect of the flash upon this temperature difference; but a study of the data and of the functions of the two types of instruments used in these measurements docs not indicate that this is a 
serious matter. 'To measure such a temperature difference is no small undertaking. To go one step farther and determine how this temperature is modified, as for example by the flash, is a different problem requiring further investigation.

In Fig. I3, C, is shown a type of (vacuum) bismuth-silver thermopile with which it is purposed to make further radiation measurements. 'This pile consists of ro junctions of silver wire $0.019 \mathrm{~mm}$. in diameter and bismuth wire $0.04 \mathrm{~mm}$. in diameter, blackened with a composition of platinum black and lamp black. The central junctions are insulated with shellac, placed in contact and backed with a receiver of pure tin, o.or mm. thick and I mm. in diameter. In air it is one-half as sensitive as a 20-element Rubeus linear thermopile. It is about 4 times as sensitive as the radiometer used to measure heat from stars, when used with a galvanometer of the same period as the radiometer. Its resistance is 19.3 ohms.

\section{THE FLUORESCENT SUBSTANCE IN FIREFLIES.}

During the plotographic work two years ago, in cleaning the test tubes which had contained fireflies, the writer noticed that the wash water had a peculiar faint bluish tinge, which he considered due to some fluorescent material. In order to demonstrate to others that it was not "blue sky," "decomposition bacteria," etc., an attempt was made to obtain a pure solution and photographs were made of the fluorescent material.*

The usual procedure to obtain a pure solution was to place the insects in a strong solution of alcohol and water. Thealbuminous material was precipitated with lead acetate and the solution was concentrated by boiling. 'The solution was then neutralized with potassium oxalate to prevent turbidity while photographing the fluorescence spectrum, which was obtained with the large spectrograph employed in photographing the light emitted by the firefly. Such a photograph of the fluorescent spectrum is shown in Plate $\mathrm{I}, C$. 'The cadmium spark produced a greater fluorescence than either zinc or aluminum, and was therefore used as an exciting source. The ultraviolet light tends to produce a cloudiness in the solution which must then be filtered. The fluorescence spectrum shows no structure and seems to be of the same nature as is commonly observed in many substances. 'The main point of interest is the extent (from $0.38 \mu$ to $0.5 \mathrm{I} \mu$ ) of the fluorescence spectrum, which is complementary with the light emitted by the firefly. (See the right-hand side of Plate $\mathrm{s}, C$, which gives the spectrum of the light emitted by Photinus.) However, no special significance is attached to this fact. 'The maximum emission of the fluorescence spectrum lies at about $0.4 \mathrm{I} \mu$. The absorption in the ultra-violet appears to be very strong, as indicated by the fact that, unless the solution is very dilute, the fluorescence extends but a few millimeters into the solution. When concentrated the solution becomes yellowish and but little fluorescence is noticeable. On dilution, however, the fluorescence reappears. 'The yellowish color is attributed to the extension of the ultra-violet absorption, of the fluorescent substance, into the visible spectrum on concentrating the solution. The material decomposes

*Coblentz, Phys. Zeit., 10, p. 955, 1909; Bull. Bur. Standards, 6, p. 32 I, I 909. 
in the light, the solution obtained two years ago showing but little fluorescence at the present time.

After searching for some time for some one versed in the chemical side of the subject, who was sufficiently interested to investigate the chemical properties of this material, Mr. F. A. MeDermott has undertaken the subject and has recently published some of the results of his preliminary tests.*

'This fluorescent material is found in great abundance in Photinus pyralis, $P$. consanguineus, and $P$. scintillans. It is also present, in somewhat less abundance, in the non-luminous genus Ellychnia corrusca, a single specimen of which is sufficient to show fluorescence in a small-sized tube contailling the alcoholic solution. Using the cadmium spark, there is no difficulty in observing the fluorescence. The fluorescent material appears to be present in only a small amount in the Photuris pennsylvanica, and is not observable immediately after placing insects in a strong solution of alcohol and water. However, after standing a few hours, the fluorescence is visible, especially when excited by the cadmium spark. All previous tests for the fluorescent material in the various species made two years ago were verified this present summer.

The rotary power of the solution of fluorescent material was tested by Messrs. Jackson and Snyder with an ordinary quartz-wedge saccharimeter. It was the extract of about 250 specimens of Photimus pyralis in 250 c.c. of water and alcohol. Using a $20 \mathrm{~cm}$. column of the solution (after treating with lead acetate), the rotation was $+0.04^{\circ}$ Ventzke. The solution was then boiled to about one-fourth to one-fifth its original volume and filtered through four thicknesses of filter paper. 'The solution was a clear yellow, but on standing a precipitate was formed. The rotation of a $20 \mathrm{~cm}$. tube of the concentrated solution was $0.21^{\circ}$ Ventzke. Using a $40 \mathrm{~cm}$. tube, the rotation was twice this amount. Since $100^{\circ}$ Ventzke $=34.657^{\circ}$ for the $D$ lines of sodium, the actual rotation was $0.073^{\circ}$ for the $D$ lines of sodium. It was concluded that, since the concentration was evidently very weak as compared with an ordinary test solution of sugar, the natural rotary power of the solution containing the fluorescent material of the firefly was very high.

The rotary power of this solution was again measured about five weeks later, the solution in the meantime having been kept in complete darkness. The small amount of precipitate present was removed just before examination. The observed rotation was $0.22^{\circ} \mathrm{V}$., from which it appears that the rotary power of the solution had changed but little, if at all, during this time.

SUPPLEMENTARY NOTE.

Since writing this paper, a recent note by Dubois (Compt. Rend., 153, p. 208, I9I I) has come to my notice in which he claims priority in the discovery of a fluorescent substance in animals, e. g., in Elaters and Lampyrids. He says he has gone a step farther than Ives and Coblentz, and McDermott, by defining its rôle physiologically and by showing that "les insectes se servent naturellement, depuis bien des siècles sans doute, de l'emploi que l'homme vient seulement de faire industriellement de substances fluorescentes pour augumenter le rendement des appareils d'éclairage, en améliorant les quali-

*McDermott, Jour. Amer. Chem. Soc., 33, p. 4 Io, 191 I. 
tés de la lumière par transformations de radiations inutiles, et même nuisibles, en clarté agréable à l'oeil et favorable à la vision."

No doubt the priority can be claimed by Dubois, who says he found the fluorescent substance in the "Luciola italica." 'I'o the writer, the 1uere discovery las been of no interest. Furtherinore, the presence of the fluorescent substance in one species of firefly is not a proof that it is to be found in all species. For example, in the Photuris ponnsylvanica there is but little of the fluorescent material, which may easily escape detection if the examination is made in white light.

Concerning the functions of the fluorescent substance, which Dubois claims is present, to modify the quality of the light enitted by the firefly in order to make it agreeable to the eye and more favorable to vision, further information must be obtained to make this assumption tenable. As mentioned elsewhere, we do not know that the rye of the insect has the sane luminosity curve as has the human eye; hence we can not say that the insect can use, the most efficiently, the same quality of light that is required by the human eye.

According to the theory of Dubois, the quality of the light emitted by the insect will depend upon the amount of violet light excited in the fluorescent substance by the light generated in the photogenic cells. 'This would be analogous to the recently developed mercury-vapor lamps backed by a diffusing screen of some phosphorescent substance, in which the color of the light of the combination is said to be decidedly different from that of the mercury are. According to this theory the bluish light of Photuris pennsylvanica would be due to the abundance of the fluorescent light added to the light produced in the photogenic cells. But the amount of fluorescent inaterial present in a single specimen of Photuris is exceedingly small, and but little of it is situated in the abdominal segments; hence, this is not a satisfactory explanation of the bluish color of the light emitted by this insect. ''urning to the Photinus pyralis we find the fluorescent material present in great abundance, so that a single specimen suffices to produce a strong fluorescence in 5 to Io c.c. of alcohol and water. 'The fluorescent material is most abundant in the wings and in the thorax, with but a small proportion in the photogenic segments. The amount of fluorescent material present in the photogenic segments is not sufficient to impart, by fluorescence, a bluish tint to the light generated in the photogenic cells, and it does not appear to be sufficient to explain the production of the observed yellowish light by absorption in passing through the fluorescent material. Indeed, it would be ponr economy to generate frequencies other than those observed and then absorb them by the fluorescent material. No doubt occasionally a specimen may be found in which the light emitted is modified by absorption, as, for example, in the sample of consanguineus mentioned on another page. This, however, was an exceptional case, in which the photogenic material extended farther than usual under the adjoining dark segment. Consequently, in passing out through the outer brown integument, the shorter frequencies (the violet) were absorbed, thus imparting a deep reddislı hue to the light emanating from the junction of the bright and dark segments. If the insect had been observed in flight, or by a casual inspection, it might easily have been said that this specimen emitted a far more reddish light than the orange-red commonly observed. Close examination was required to show that this departure from the ordinary orange-red did not extend over the entire luminous segments. 


\section{INFRA-RED ABSORPTION MEASUREMENTS.}

In view of the fact that it has been impossible to detect infra-red radiation emanating from the firefly, the question arose as to wlicther there is no infrared radiation, or whether the radiation is absorbed after it leaves the photogenic cells. Obviously there can be but little infra-red radiation absorbed without special provision to keep the temperature normal, otherwise the insect would become lot. 'The solution of this question was undertaken from two points of view. Ives* searched for radiation lying between $0.7 \mu$ and $\mathrm{I} .5 \mu$ by noting the extinguishing action tupon the phosphorescence of Sidot blende when exposed directly to the light of the firefly, and when a plate of red glass was interposed. Exposing the phosphorescing plate directly to the light of the firefly, the intensity of the phosphorescence was markedly reduced in half an hour, but exposing the plate through red glass for $3 \frac{1}{2}$ hours liad no reducing effect upon the intensity of the phospliorescence of the Sidot blende. Since the reducing effect was practically the

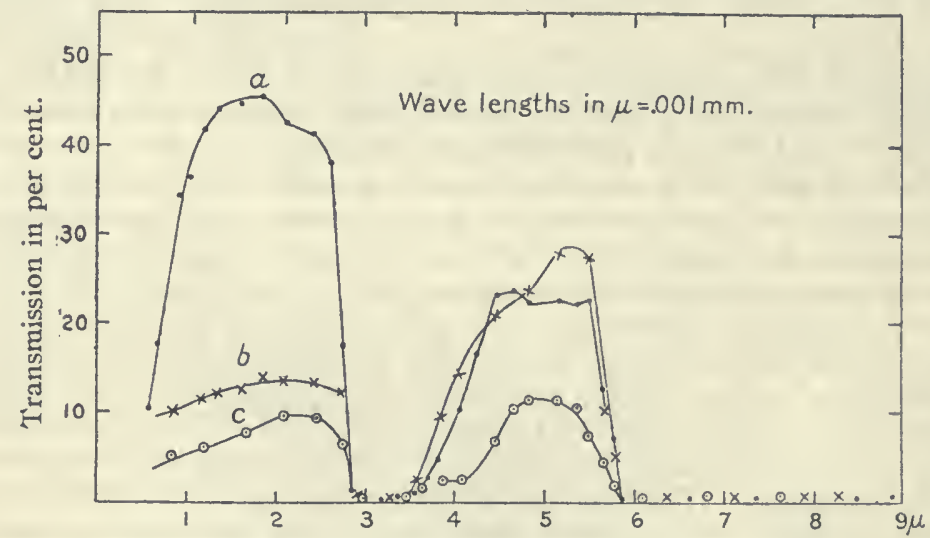

Fig. I 4.-Transmissivity of the integument of fireflies.

same for the infra-red to $1.5 \mu$ as for the visible, it was concluded that 110 radiations lying between $0.7 \mu$ and $\mathrm{I} .5 \mu$ were emitted. Using a quartz spectrograph, no emission conld be detected in the ultra-violet. 'The writer attacked the problem $\uparrow$ by examining the opacity of the outer integument (the chitinous layer) of various fireflies for different regions of the infra-red. For, assuming that appreciable radiation is generated in the photogenic cells, it is important to learn what frequencies can pass out into space.

In Fig. 14 , curve $a$ gives the transmission through one of the horny abdominal segments of a dried specimen of the Cuban firefly, Pyrophorus noctilucus. This integument is dark brown (in reflected light), which causes lieavy absorption through the visible spectrum to the red, at which point the transmission increases rapidly. In this firefly, it may be recalled, the abdominal light is emitted through a slit between two of the segments, of which the

*Ives, Phys. Rev., 31, p. 637, 1910; Electrical World, 56, Oct. 1 3, 1910.

†Flectrical World, 56, p. IOI 2, I910; also 54, p. I I84, I 909. 
above is a sample. The size of the specimen examined was about $1.5 X$ $7 \mathrm{~mm}$. In this same illustration, Fig. 14, curve $b$ gives the transmission through one of the eye-like fenestrate membranes on the thorax of the Cuban firefly, and through which is emitted the so-called "thoracic light." The specimen was only $1.5 \times 2 \mathrm{~mm}$., and hence very difficult to examine. After removing all the photogenic cell ligaments which adhered to it this specimen was fairly translucent. In the region from $I \mu$ to $2 \mu$ the transmissivity is probably higher than observed, the low values being due to scattering of the radiation in passing through the specimen.

Curve $c$, Fig. I4, gives the transmission through the outer integument covering the plotogenic cells of Pholimus pyralis. 'The specimen examined was a single dried abdominal segment, $1.5 \times 4 \mathrm{~mm}$., which had been moistened in water and freed from all ligaments and photogenic material. 'The specimen was not very smooth and it was only semi-translucent. No doubt a better sample could have been prepared by dissecting a fresh undried insect. In both curves, $b$ and $c$, the opacity at $\mathrm{I}$ to $2 \mu$ and at $5 \mu$ is greatly increased by scattering of the transmitted radiation which did not reach the bolometer. However, as was anticipated in previous communications, these curves have the characteristic absorption spectrum of complex carbohydrates, in which there is great (and usually complete) opacity from $2.8 \mu$ to $3.8 \mu$, and beyond $6 \mu$, with a fairly transparent region at $4.5 \mu$ to $5 \mu$. It may be noticed that these specimens were dry. If they had been fresh, then the water present would have absorbed considerable of the radiation at 4 to $5 \mu$.

During the present summer an examination was made of the infra-red absorption of the fresh photogenic substance of Photinus pyralis, excised and placed between fluorite plates. The material was an inhomogeneous white mass, which in the preliminary examination showed complete opacity from $3 \mu$ to $3.8 \mu$, a more transparent region at 4.5 to $5.5 \mu$, followed by complete opacity beyond $5.8 \mu$. This is the same sort of absorption as found in the chitinous layer, Fig. I4. A thin layer of the white fluorescent fluid which exudes freely from the wings of the pyralis was also examined between fluorite plates. Complete opacity was observed from 2.9 to $3.2 \mu$ and beyond $5.8 \mu$; and an appreciable absorption band was observed at $4.7 \mu$. These bands were considered to be due to water, and since no others were observed a more thorough examination seemed unnecessary. Apparently the fluorescent material has no appreciable absorption bands in this region of the spectrum.

The experiments of Ives have bridged the gap from the visible to $r .5 \mu$. The data then published by the writer showed that but little if any radiation of wave-lengths'greater than $2.5 \mu$ would pass out into space even if generated in the photogenic cells. That which can beemitted at $4.5 \mu$ to $5.5 \mu$ will be so weak in intensity that it will hardly be distinguished from the emission spectrum due to the "animal heat" (maximum emission at 8 to $10 \mu$ ) radiated from the surface of the body. By exclusion, we have, therefore, reduced the unexplored region to that part of the spectrum lying between the wavelengths $\mathrm{I} .5 \mu$ and $2.5 \mu$. There are no types of radiators known which would lead one to expect emission bands in this region of the spectrum of the light of the firefly, and while it is important to be on the alert for the unexpected, 
it seems just as probable that the explanation will be found in biochemical phenomena not requiring the production of radiations of low frequency in order to produce a given amount of light. Set as we are in our ways of thinking, we insist that the methods employed by the firefly to produce its light must be similar to our own. We might as legitimately suppose that the combustion of food in our bodies, with the resultant formation of $\mathrm{CO}_{2}$ and $\mathrm{H}_{2} \mathrm{O}$, or that the combustion in a growing leaf, must be accompanied by a rise in temperature and emission of radiant energy (other than "animal heat") simply because we observe all these phenomena when we light a candle or heave coal into the fire.

In recent papers* the writer has published numerous illustrations showing that in incandescent solids and in gases excited in vacuum tubes the production of light is accompanied by a very considerable amount of infra-red radiation; that in the arc light, especially the "flaming are" vapors, there is little infra-red radiation; and that in the high-frequency spark nearly all the radiation is in the ultra-violet. The light of the firefly is not unlike that of an ideal radiator at a temperature of $5,000^{\circ}$, differing from it only in the density of the radiation. If the speeific emissivity of the sun were as low as that of the firefly, it is quite possible that no infra-red radiation could be detected. The solar corona is another example of this type. Perhaps the question may become clearer when we can formulate some ideas on the emissivity from a selectively absorbing substance in the region of a band of anomalous dispersion. 'The ideal radiator is one having no reflectivity. Only in the region of anomalous dispersion, where the refractive index becomes practically $n i l$, is this condition fulfilled, as far as the reflecting power is concerned.

*Jahrb. der Radioaktivität und Electronik, vir, p. r23, 1910; Illuminating Eingineer, London, 3, p. I, I910. 


\section{NATURE OF THE LIGHT EMITTED BY FIREFLIES.}

It is beyond the scope of the present paper to discuss the various experiments which have been made in the endeavor to learn how the firefly produces its light. 'The older publications usually contain bibliograplies which may be consulted,* and on the following pages only such data are quoted as have a very direct bearing on the subject.

'The old idea that the light in animals is duc to plosphorus has long been refuted. The idea has also prevailed that the light is a species of phosphorescence. During the past fifty years various experiments have been made which could have been used to refute this idea; but, owing no doubt to the lack of a thorough knowledge of the behavior of phosphorescent materials, not until within the past few years has this erroneous notion been losing adherents. The phosphorescence idea no doubt originated from the fact that some fireflies appear to be most active at dusk. This observation of the time of greatest activity in fireflies depends of course upon the extent of the experimenter's knowledge of the habits of the various species, some of which do not appear until after it is dark, and are very active for hours thereafter, although it would not appear so to the casual observer, for the reason that most of their activity (e. g., Photuris) is among the tops of tall trees.

The most important characteristics of phosphorescent material are ( $\mathrm{x}$ ) the production of a "phosphorescent light" which continues to be emitted for some time after exposure to white light and especially to violet and ultraviolet light; and (2) the extinction of this "phosphorescent light" on exposing the glowing material to infra-red rays. Some substances (e.g., fluorite) emit a phosphorescent light, called thermo-luminescence, when heated to from $50^{\circ}$ to $200^{\circ} \mathrm{C}$. Although the application of heat to insects has been made from the beginning, it can not be a test for thermo-luminescence in the living insect, because of the question of the heat acting as an irritant.

One of the first experiments tried by the writer, four summers ago, was the effect of heat and cold (liquid air), of light and of darkness, upon living and upon dead insects. The dry specimens showed no thermo-luminescent light on heating; neither was there a phosphorescence when exposed to light. The luminous organs of freshly killed, undried specimens did not show phosphorescence when exposed to white light or to the ultra-violet spark. Both last year and this year the effect of $\mathrm{X}$-rays was tried on fireflies, but neither phosphorescence nor fluorescence could be detected. In the same manner the precipitate from the fluorescent material found in the body fluid of fireflies, dried on filter paper, was not excited to luminescence by the X-rays or violet light. These experiments are of interest in connection with the data showing that photogenic material may be kept in a dry state for a long time when it can be made to glow by treating it chemically. Evidently the photogenic niaterial does not possess phosphorescent properties.

\footnotetext{
"Langley, "Cheapest form of light," Amer. Jour. Sci. (3) 40, No. 236, 1890.

Seaman, The luminous organs of insects, Proc. Amer. Soc. Micros., 13-14, p. 133, I89I-2.

Watase, A treatise on the luminosity of insects.

Mangold, "Die Produktion von Licht," Winterstein's Handb. der Vergleich. Physiologie, Band 3, 1911.
} 
In parenthesis it may be added that the light of the firefly did not produce fluorescence on the platinum barium cyanide screen, which is sensitive to $\mathrm{X}$-rays. According to Mangold (1. c.) the older experiments, which indicated that fireflies emit X-rays, have long since been shown to be erroneous. In his recent experiments, Ives* also has investigated the question of phosphorescence and the conclusion arrived at is that the light of the firefly has none of the properties of true pliosphorescence.

'The oxidation theory has called forth more experiments than the theories just mentioned. 'To this end the firefly has been subjected to all sorts of tests. For example, meclianical stimulation, such as percussion, pressure, etc., causes the quiescent, dark photogenic organs to burst into a glow. The application of heat or electric current causes the organs to glow. In a vacuum the freshly excised quiescent luminous organs have been found by the writer to remain so, but on admitting air they glowed with great brilliancy. The color of the light was the same as the ordinary glow in the living specimen.

The experiments on the action of cliemical stimuli are very numerous, no less than 68 different substances having been tried. These substances include gases and vapors; also liquids and solutions of acids, alkalies, salts, and alkaloids. 'The most recent work along this line is by Kastle and McDermott, $\uparrow$ whose paper should be consulted, not only for their own contributions, but also for their references (see appended Bibliography) to similar tests by earlier experimenters. 'These experiments show that certain substances distinctly stimulate the light production; that others distinctly inhibit the luminescence; and that still others have little or 110 effect on the light production. No definite relationship was found between chemical composition and the power to excite the living photogenic material to luminescence. The main point of interest is that anæsthetics and related compounds act as a powerful stimulus to the light production.

Probably the most important observation is the effect of water on the production of light by the photogenic material. As early as 1798 Carradori observed that the light emission is suspended by drying the photogenic organs and is revived again by softening in water. 'This phenomenon has been repeatedly verified by subsequent observers. Kastle and McDermott have kept the dry material in sealed glass tubes for 13 months (to Sept. 9, 1910; at the present writing almost two years have elapsed and the tests show that the photogenic material is still active), at the expiration of which time the specimens glowed actively for 15 minutes when moistened with water in the presence of oxygen. This moistening and redrying was repeated four times before the material ceased glowing. . Using hydrogen peroxide solution in place of water, the glow was more intense.

In the conclusions to be drawn from the chemical aspect of the processes involved in the production of light by living organisms, three factors are required, viz, water, oxygen, and a substance to be oxidized. Just what the substance is that is oxidized is not known. Some have assumed it to be a fat, or an albuminous body. The histological study shows that the photo-

*Ives, Phys. Rev., 31, p. 637, 1910.

†Kastle and McDermott, Amer. Jour. Physiology, 27, p. 122, 1910. 
genic layer and the so-called "reflecting layer" are penetrated by innumerable tracheæ, which are supposed to be filled with air. During the experiments recorded herewith, it was found that the fireflies must have access to plenty of fresh air to keep them healthy and active. In fact, to the writer it appeared that they required more fresh air (oxygen) than would be required in the ordinary respiratory processes. Other insects (e. g., several nonluminous Elaters) did not seem so sensitive in this respect.

While it is generally accepted that the light production is connected in some manner with an oxidation process, there is no data showing how the light emission is brought about. Optically the so-called "reflecting layer" has little if any meaning. Whether it is the storehouse for waste products or (what is more plausible) a reservoir containing an oxidizable substance is a subject deserving further consideration. As mentioned elsewhere, it would be desirable to learn the condition of this layer with the age of the insect, and especially after it has flashed for a long time. Since samples of Photuris can be obtained which will flash in rapid succession for at least $\mathrm{I}$ to $1 \frac{1}{2}$ hours, it would be interesting to compare its "reflecting layer" with that of a specimen which has not flashed in this manner. But while this may give some information in regard to the light production in fireflies, it will hardly apply to all organisms. In some organisms the light is developed in a less highly organized cell; and, indeed, in the case of some marine animals a liquid is ejected which becomes luminous on diffusing in the water. In this connection Dubois has already been quoted that the light is produced when the ejected liquid passes from a colloidal into a crystalline state. Ultimately it may perhaps be shown that the light production is the result of energy transformations in passing from the colloidal to the crystalline state. In this connection the optical properties of thermo-luminescent fluorites has been the subject of some study by the writer, but no definite results have yet been obtained. Just what happens when fluorite is warmed and the thermo-luminescence destroyed is not known. Whether this lias any bearing on the light emission in animals is difficult to determine.

Washington, D. C., Seplember I, IOII. 


\section{Explanation of Plate.}

A. Photograph of the spectrum of a carbon glow-lamp, for different exposures.

B. Spectra of: (I) helium vacuum tube; (2) "4-watt" carbon glow-lamp; (3) firefly Photinus pyralis, taken in 1909; (4) and (7) firefly Photuris pennsylvanica; (5) and (6) firefly Photinus pyralis, taken in 1911.

C. Spectra of: (I) helium vacuum tube; (2) from $0.3889 \mu$ to $0.4922 \mu$ : fluorescence spectrum of a substance found in the blood of fireflies, e. g., in Photinus pyralis;

(2) from $0.5015 \mu$ to $0.6678 \mu$, spectrum of light enitted by Photinus pyralis;

(3) same as (2) from $0.5015 \mu$ to $0.6678 \mu$, using a shorter exposure.

D. Photographs obtained with short-focus spectrograph:

Photuris pennsylanica, I: 8,9 , I2, I3. II: 9, IO. III: IO, II, I2. IV: $6,7$. V: $7,8,9$. VI: $2,5,6$. VII: $2,3,4$.

Photinus pyralis, I: 2 to 7. II: 2 to 8 and 14 . III: 2 to 9 and 13,14 . IV: 2 to 5 and 8 to I4. V: 2 to 6 and ro to I4. VI: 7 to I 4 . VII: ro to I4.

Photinus consanguinens, I: II. II: II, I2. VII: $5,6,7,8,9$.

Photinus scintillans, I: I4.

Glow-worm, II: I3.

Helium comparison spectrum, VI: 3 , wave-lengths from left to right $0.47 \mathrm{I}, 0.492$, $0.501,0.587$, and $0.667 \mu$. I: Io, yellow helium line, $\lambda=0.5876 \mu$. (0.501 $\mu$ is faint.)

In $\mathrm{D}$, column $\mathrm{I}$ is made up of two plates. The succeeding columns, II to VII inclusive, are reproductions of single plates containing a dozen or more exposures to firefly light, with the helium comparison spectrum at the beginuing and the end of each series. The original negatives are of course much stronger in the red than here reproduced. 

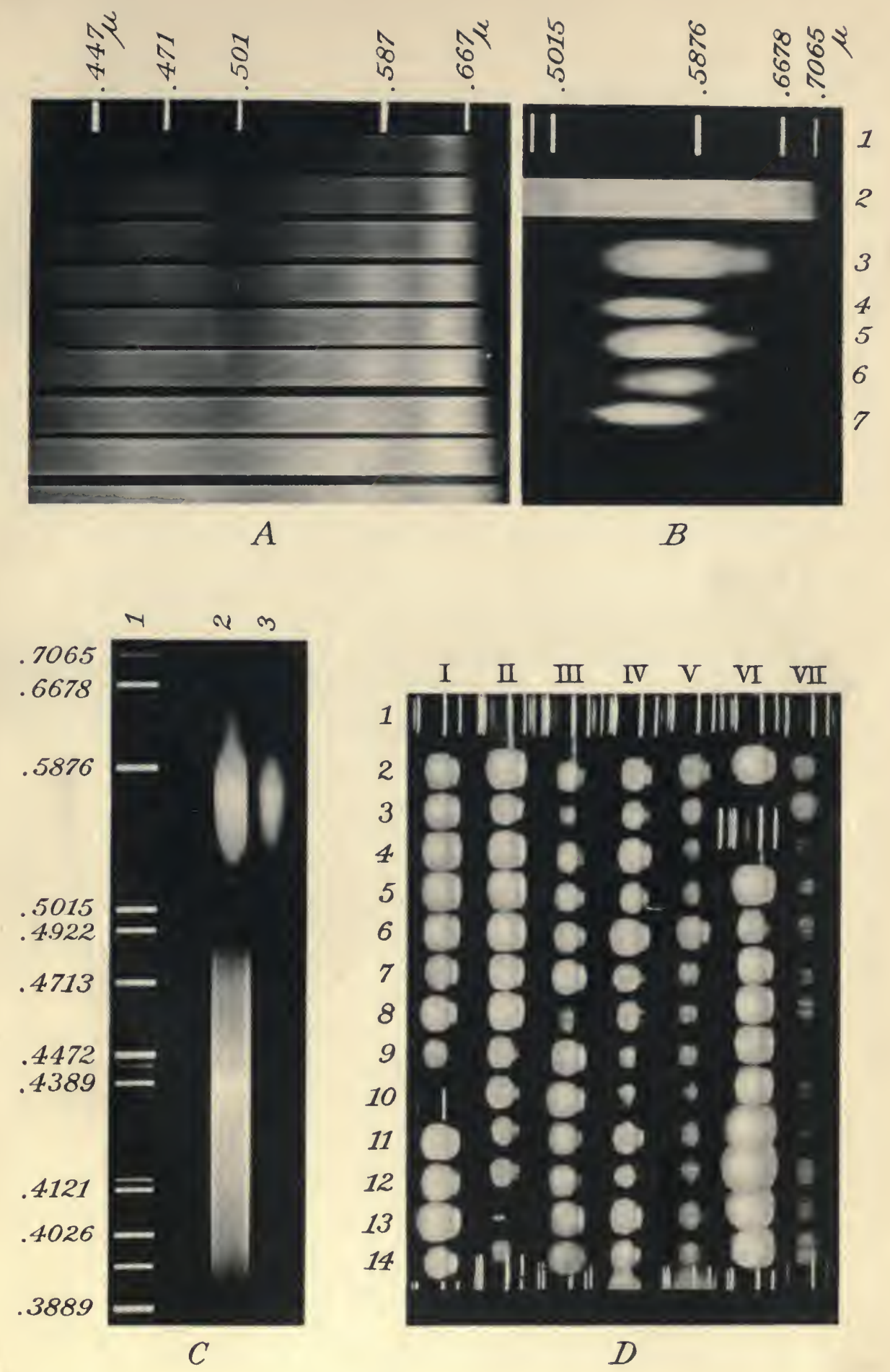



\section{BIBLIOGRAPHY.}

Artaud: Annales maritimes et coloniales, 1825, p. 364; Bulletin des sciences mathématiques, I 826, vi, p. I29; Journal für Chemie and Physik, 1828, L1I, pp. 319-323.

Bischoff: Journal für Chemie und Physik, I823, Xxxıx, pp. 259-305.

Bongardt: Zeitschrift für wissenschaftlische Zoölogie, 1903, LXxV, pp. 1-45.

Carradori: Annales de chimie, 1798, xxrv, pp. 96-Ior; Annalen der Physik, 1799, I, pp. 205-213; Philosophical magazine, 1798, II, pp. 77-80; Giornale di fiscia, chimia e storia naturale, I 808, I, pp. 269-280 and I 809. II, pp. 247-264.

Carus: Comptes rendus de l'Académie des sciences, I864, LIX, pp. 607-608.

Dubois: Bulletin de la société zoölogique de France, 1886, XI, pp. 1-275; Comptes rendus de l'Académie des sciences, 1887, cv, pp. 690-692; Ibid., 1886, cXXIII, pp. 653-654.

Ehrenberg: Abhandlungen der königlich-preussische Akademic der Wissenschaften, Berlin, I 834 , pp. 4 I I -575 .

Faraday: Life and Letters, by Bence-Jones, I, pp. 90, 91, 125, 14I, I42, 144-146.

Forster: Observations sur la physique, 1783 , XxII, p. 24; Magazin der Wissenschaften und Literatur, I 783 , Pt. Ix, p. 281.

Giesbrecht: Mittheilungen aus def zoölogische Station der Neapel, I893-1985, XI, pp. $648-690$.

Grotthuss: Annales de chimie, 1807, LXIv, pp. 19-41 (38-40).

Heinemann: Archiv für mikroskopische Anatomie, 1872, viII, pp. 46I-47 I (see also Archiv für die gesammte Physiologie, 1873, vII, pp. 365-366; Archiv. für mikrokopische Anatomie, 1886, xxvir, pp. 296-382; Pyrophores, Vera Cruz, 1887).

Heinrichs: Die Phosphorescenz der Körper, Nürnberg, I 820.

Henneguy: Comptes rendus de la société de biologie, I 888,8 sér., pp. 707-708.

Holder: Living Lights, New York and London, 1887,8 vo.

Humboldt: Tableaux de la nature; Paris, I85I, II, pp. 60 et seq.

Jousset de Bellesme: Journal de l'anatomie et physiologie I880, XVI, pp. I2I-I69; Comptes rendus de l'Académie des sciences, 1880, Xc, pp. 318-321; Revue médicale de France et étranger, i 800 , I, pp. 287-29 I.

Ives and Coblentz: Bulletin of Bureau of Standards, Washington, I 9 Io, vi, pp. 32 I -336.

Kolliker: Verhandlungen der Würzburg physikal-medicinische Gescllschaft, I857, viI, pp. 21 7-224; Journal of Miscroscopical Science, 1858, v1, pp. 166-173.

McDermott: Popular Science Monthly, I9I0, LXXVII, pp. I I4-121.

Macaire: Annales de chimie et de physique, 1821, Xvir, pp. 151-167; Annalen der Physik, I822, Ixx, pp. 265-280; Quarterly Journal of Science, 1822, XII, pp. 18I-182; Journal de physique, 1821 , Xcirr, pp. 46-56.

Macartney: Philosophical Transactions of the Royal Society, i8 1o, c, pp. 258-293; Annalen der Physik, I819, LxI, pp. 1-35; Journal of Natural Philosophy, Chemistry, and the Arts, $181 \mathrm{I}$, XxvirI, pp. 4I-45; Journal für Chemie und Physik, 18 14, x, pp. 409-444.

Meyen: Novorum actorum academiæ cæsareæ Leopoldino-Carolinæ Germanicæ naturæ curiosum, xvi, Supplement.

Michaels: Ueber das Leuchten der Ostee, Hamburg, I 830.

Milne=Edwards: L,eçons sur l'anatomie et la physiologie comparée de l'homme et des animaux, 1863, viII, leç. 68 , pp. 83-120.

Panceri: Annales des sciences naturelles, 1872, xvr, 5 sér., pp. I-67.

Peters: Journal of Experimental Zoölogy, 1905, LIX, pp. 235-242.

Pfaff: Journal für Chemie und Physik, i 828, LII, pp. 3 I I-32 I.

Pflüger: Archiv. für die gesammte Physiologie, 1875, XI, pp. 222-263 (see also Ibid., $1875, \mathrm{x}$, pp. $25 \mathrm{I}-367$ )

Quoy and Gaimard: Annales des sciences naturelles, 1825, IV, p. 8.

Spallanzani: Memoria della Societa Italiano, Verona, I 794, vII, pp. 27 I-290; Chimico esame degli esperimenti del Sig. Gottling, Professor a Jena, sopra la luce del fosforo, etc., Modena, I 796.

Tiedemann: Physiologie de 1'homme, Paris, I831, II, pp. 516-55I.

Tilesius: Neuer Annalen der Wetteranischen Gesellschaft, für die gesammten Natırkunde, 18 I 8 , IV, p. 74 . 





QL Coblentz, William Weber

596 A physical study of the MRC6 firefly

BioMed.

PLEASE DO NOT REMOVE

CARDS OR SLIPS FROM THIS POCKET

UNIVERSITY OF TORONTO LIBRARY 
